\title{
Identifying the key challenges for fog and low stratus forecasting in complex terrain
}

\section{Journal Article}

\section{Author(s):}

Westerhuis, Stephanie (i); Fuhrer, Oliver (D); Cermak, Jan; Eugster, Werner (i)

Publication date:

2020-10

Permanent link:

https://doi.org/10.3929/ethz-b-000438688

Rights / license:

In Copyright - Non-Commercial Use Permitted

Originally published in:

Quarterly Journal of the Royal Meteorological Society 146(732), https://doi.org/10.1002/qj.3849

Funding acknowledgement:

ETH-17 16-2 - Towards an operational fog forecasting system (Fog4Cast) (ETHZ) 


\title{
Identifying the key challenges for fog and low stratus forecasting in complex terrain
}

\author{
Stephanie Westerhuis ${ }^{1,2}$, Oliver Fuhrer ${ }^{2,3}$, Jan Cermak ${ }^{4,5}$, and Werner \\ Eugster ${ }^{1}$ \\ ${ }^{1}$ ETH Zürich, Department of Environmental Systems Science, Zürich, \\ Switzerland \\ 2 MeteoSwiss, Zürich, Switzerland \\ ${ }^{3}$ Vulcan Inc, Seattle, USA \\ ${ }^{4}$ Karlsruhe Institute of Technology, Institute of Meteorology and Climate \\ Research, Karlsruhe, Germany \\ ${ }^{5}$ Karlsruhe Institute of Technology, Institute of Photogrammetry and \\ Remote Sensing, Karlsruhe, Germany
}

November 3, 2020

This is the peer reviewed version of the following article: Westerhuis S, Fuhrer $O$, Cermak J, Eugster W. Identifying the key challenges for fog and low stratus forecasting in complex terrain. Q.J.R. Meteorol. Soc.. 2020, which has been published in final form at https://doi.org/10.1002/qj.3849. This article may be used for noncommercial purposes in accordance with Wiley Terms and Conditions for Use of Self-Archived Versions. 


\begin{abstract}
Accurately forecasting fog and low stratus (FLS) poses a challenge to current numerical weather prediction models despite many advancements in recent years. We present a novel method to quantify FLS extent bias by comparing forecasts to satellite observations. Evaluating a four-month period we show that COSMO-1, the MeteoSwiss high-resolution operational model, exhibits a considerable negative FLS bias during wintertime. To study the cause, we conduct a series of sensitivity experiments for a representative case study, where COSMO1 erroneously dissipated extensive FLS.

Replacing the one-moment bulk microphysics parameterisation scheme by a two-moment scheme as well as increasing the number of vertical levels did not show any improvements. The FLS dissipation was delayed (but not prevented) by decreasing the lower bound imposed on the turbulent diffusion coefficients from $0.4 \mathrm{~m}^{2} / \mathrm{s}$ to $0.01 \mathrm{~m}^{2} / \mathrm{s}$, or by reducing horizontal grid spacing from $1.1 \mathrm{~km}$ to $550 \mathrm{~m}$. Additionally, simulations at $1.1 \mathrm{~km}$ grid spacing with smoothed orography led to more extensive FLS than the same simulations without smoothed orography. An analysis of the cloud water budget revealed that the model's advection scheme is causing a loss of liquid water content near the cloud top. A simulation with an alternative terrain-following coordinate system in which the vertical coordinates are quasi-horizontal near the cloud top reduced the loss of cloud water through advection and improved the evolution of the FLS in the case study.

In combination, our findings suggest that the advection scheme exhibits numerical diffusion which promotes spurious mixing in the vertical of cloudy and adjacent cloud-free grid cells in terrain-following vertical coordinates; this process can become the root cause for too rapid dissipation of FLS during nighttime in complex terrain.
\end{abstract}

\title{
1 Introduction
}

Fog and low stratus (FLS) can have considerable socioeconomic impacts. Köhler et al. (2017) show that photovoltaic power prediction errors related to FLS occurrence endanger the stability of the electric grid. Further, by reducing visibility at the surface, fog poses a threat to all modes of human transportation, especially at airports (Gultepe et al., 2007; Roquelaure and Bergot, 2009; Stolaki et al., 2012; Kulkarni et al., 2019). 
Many studies over the past decades have shown that forecasting FLS is a difficult task (Teixeira, 1999; Gultepe et al., 2007; Bergot et al., 2007; Van der Velde et al., 2010; Zhou et al., 2012; Szintai et al., 2015; Belo-Pereira and Santos, 2016; Pu et al., 2016; Pithani et al., 2019a; Román-Cascón et al., 2019). Various aspects have been identified in the literature as important for successful FLS modelling of which the following are considered to have the highest impact: To begin with, an adequate model initialisation is crucial; local observations are essential in this context (Bergot et al., 2007; Rémy and Bergot, 2009) and accurate surface datasets are required (Boutle et al., 2016; Pu et al., 2016). Second, FLS modelling critically depends on the parameterisation schemes employed to represent processes which are not explicitly resolved by the numerical grid. And third, the model's capability to represent and evolve the grid-scale features into the future.

In recent years, a lot of research has been conducted on parameterisations: In an intercomparison study of various setups of the Weather Research and Forecasting (WRF) model in single-column mode, Steeneveld and de Bode (2018) identified boundary layer mixing and soil conductivity as well as their non-linear interactions as the most influential model parameters for a radiation fog case in the Netherlands. For the three-dimensional version of the WRF model, Steeneveld et al. (2015) demonstrated the model's high sensitivity to the choice of boundary layer and microphysics parameterisation. Among others, Müller et al. (2010) and Schwenkel and Maronga (2018) stress the need for sophisticated microphysics schemes. Both, Pithani et al. (2019b, for the Indo-Gangetic basin) and Chachere and Pu (2019, for the Salt Lake Valley), report difficulties to find an optimal combination of microphysics and boundary layer parameterisation.

FLS modelling requires sufficiently high resolution in the vertical (Tardif, 2007; Pithani et al., 2019b) Many of the cited studies employ horizontal grid spacing of only few kilometers. Boutle et al. (2016) demonstrate benefits of decreasing the grid spacing beyond the kilometre-scale, which is particularly relevant in complex terrain (Gultepe et al., 2014).

It is difficult to address the problem of FLS forecasting in a universal way; overall, there is no clear consensus on one individual model component at which research efforts should be directed for improved representation of FLS in high-resolution numerical weather prediction (NWP) models (Bergot et al., 2007; Román Cascón et al., 
2012; Chachere and $\mathrm{Pu}, 2019)$.

In this work, we focus on forecasts of wintertime FLS in complex terrain. Pu et al. (2016) conclude that accurate fog forecasts in complex terrain are particularly challenging, as the WRF model employed to issue forecasts for the MATERHORN-Fog project (Gultepe et al., 2016) produced large errors in near-surface variables. We aim at improving the representation of FLS in a high-resolution NWP model which is used in an operational context and hence not specifically designed for FLS. To that end, we evaluate the impact of applying changes to the model as suggested from literature. We apply a mesoscale perspective by investigating FLS on the Swiss Plateau which comprises an area of more than $15,000 \mathrm{~km}^{2}$. More background information about FLS over the Swiss Plateau is given in Section 2.

To evaluate FLS forecasts for such an extensive area, we make use of satellite imagery. We present a method how to objectively compare the FLS extent forecasted with a NWP model with observations obtained from satellite imagery (Section 3).

We conduct simulations with the high-resolution version of the COSMO model (developed jointly by the Consortium for Small-scale Modelling), COSMO-1 (details are given in Section 4). Forecasters at the Federal Office of Meteorology and Climatology, MeteoSwiss, rely on COSMO-1 for predicting FLS conditions for the general public and a diverse range of customers including the airport authorities.

The satellite-based evaluation of four months of COSMO-1 forecasts shows that the model often underpredicts FLS over the Swiss Plateau. To determine the reason for this behaviour, we present a model analysis and experiments for a selected case in which the discrepancy between forecast and reality was very obvious and thus allows for detailed exploration of the underlying model mechanisms that have led to this (Section 5).

Finally, we summarise our findings and suggest future perspectives (Section 6).

\section{Background on FLS over the Swiss Plateau}

This section provides the necessary background information on fog and low stratus in the geographical region of the Swiss Plateau for which COSMO-1 should be improved. Observations available to validate model performance and potential improvements are then introduced in Section 3. 
The Swiss Plateau is a highly populated area and includes the most important Swiss airports in Zürich (ZRH) and Geneva (GVA). Especially ZRH is prone to weather situations with fog. Although the number of fog days has decreased since the 1970ies-probably not only related to climate change but also improvements in air quality (Klemm and Lin, 2016)—on average 50 days per year with fog occurrence were reported during the last decades (visibility below $1 \mathrm{~km}$, observations issued by a human observer at 0640 UTC, 1240 UTC, and 1840 UTC.; Fig. 1). The Swiss Plateau is covered by FLS throughout the whole day on typically 3.5 to 5 days per month during November, December, and January (Scherrer and Appenzeller, 2014).

The Swiss Plateau is an orographic basin at about $400 \mathrm{~m}$ above sea level (asl) bordered by the Jura mountain range in the north (with crests between $1000 \mathrm{~m}$ and $1700 \mathrm{~m}$ asl) and the Alps in the south (with summits exceeding $4000 \mathrm{~m}$ asl). Even though the Swiss Plateau constitutes the flattest part in Switzerland, it is rolling terrain with elevational differences of several hundreds of meters.

During the night, cold air accumulates in this basin-mostly driven by radiative cooling-and a temperature inversion builds up (Müller et al., 2010). In winter, when nights are long and daytime solar heating is reduced, the air close to the surface is continually cooled and eventually can become saturated-a process promoted by clear skies and calm conditions (Brown and Roach, 1976; Roach et al., 1976). Even during the cold season the typical persistent fog layer remains at temperatures around freezing near the ground (see Fig. A.1 in the Appendix) and is therefore too warm to be classified as "cold fog" (Gultepe et al., 2015).

The vertical extent of the accumulated cold air determines whether FLS-if presentclassifies as a cloud touching the surface, and thus should be termed "fog", or whether it should be termed "low stratus", as it does not touch the ground (Wanner, 1979). Once formed, especially under anticyclonic weather situations, FLS can either persist for multiple days or repeatedly redevelop every night. Until FLS fully dissipates (usually due to a complete change in air mass associated with a front) its structure undergoes continuous development in both vertical and horizontal extent.

A pressure gradient decreasing from north to south associated with mostly northeasterly winds, so-called "Bise" (Wanner and Furger, 1990), favours wide-spread low stratus with cloud tops above $1000 \mathrm{~m}$ asl. A pressure gradient from south to north, often accompanied by southwesterly winds, generally leads to lower stratus 
and fog which are thus confined to smaller areas (Courvoisier, 1976; Wanner, 1979; Bachmann and Bendix, 1993). Overall, low stratus occurs more frequently than fog over the Swiss Plateau (Egli et al., 2018).

To summarise, the FLS development over the Swiss Plateau is multifaceted and the various situations cannot be fully described by simple conceptual models. While radiative cooling is one of the main drivers for FLS occurrence over the Swiss Plateau, advective processes contribute to the FLS development, and therefore fully three-dimensional models are required for its prediction (Müller et al., 2010).

\section{Observations}

\subsection{Objective verification based on satellite imagery}

To objectively assess the modelled FLS extent as well as time of formation and dissipation in a quantitative manner we define an area of interest surrounding the Swiss Plateau (orange polygon in Fig. 2). It comprises $N=19,225$ grid cells, covers an area of $23,262 \mathrm{~km}^{2}$ and stretches $360 \mathrm{~km}$ from the southwestern to the northeastern corner. For this area, we calculate a cloud fraction bias $\left(B_{C F}\right)$ as the normalised difference of the fraction of grid cells with FLS in the model forecast $\left(n_{\text {model }}\right)$ and in the satellite imagery $\left(n_{\text {satellite }}\right)$ :

$$
B_{C F}=\frac{n_{\text {model }}-n_{\text {satellite }}}{N},
$$

$n_{\text {model }}$ comprises all grid cells where the liquid water path (LWP) exceeds $0.2 \mathrm{~g} / \mathrm{m}^{2}$ and $n_{\text {satellite }}$ denotes the number of grid cells covered by FLS detected with a confidence level above a certain threshold. In order to ensure a robust operation regardless of the time of day, a satellite technique based purely on infrared information is used. To derive a FLS confidence level $\left(C L_{F L S}\right)$ from satellite imagery, we make use of the different radiative properties of ice and liquid water clouds. We use the $8.7 \mu \mathrm{m}$ and $12 \mu \mathrm{m}$ bands ( $T_{12 \mu \mathrm{m}}$ and $T_{8.7 \mu m}$ in Eq. 2 ) of the Spinning Enhanced Visible and Infrared Imager (SEVIRI) aboard the Meteosat Second Generation (MSG) satellite (Schmetz et al., 2002). This system scans the hemisphere every $15 \mathrm{~min}$ and has a nadir nominal spatial resolution of $3 \mathrm{~km}$, which results in a resolution of roughly $4 \mathrm{~km}$ (meridional) $\times 6 \mathrm{~km}$ (zonal) over Switzerland (Buhler et al., 2017). 
Compared to ice, liquid water has a higher absorption coefficient in the $12 \mu \mathrm{m}$ spectrum, while both ice and liquid water are comparable in the $8.7 \mu \mathrm{m}$ spectrum, and clear-sky brightness temperature does not differ much between the two spectra (Strabala et al., 1994). This principle has been successfully implemented and described in detail in a FLS detection technique by Andersen and Cermak (2018). For the purpose of this study, the spectral component of this technique is implemented as follows:

$$
C L_{F L S}=\frac{T_{L C}-\left(T_{12 \mu m}-T_{8.7 \mu m}\right)-T_{C C R}}{2 \times T_{C C R}} .
$$

$T_{L C}=1.8 \mathrm{~K}$ describes the threshold for liquid clouds and $T_{C C R}=1 \mathrm{~K}$ denotes the cloud confidence range between this threshold and a certain clear vs cloudy pixel. These two parameters were determined by radiative transfer calculations with the STREAMER model (Key and Schweiger, 1998), and empirically adjusted by systematic qualitative evaluation of a large number of satellite scenes.

Higher-level clouds, in the ice and liquid phases obscure the signal from underlying clouds regularly (Cermak, 2018). To account for this, we exclude samples where more than $10 \%$ of the grid cells in the area of interest exhibit a temperature signal below $263 \mathrm{~K}$ in the $10.8 \mu \mathrm{m}$ channel. Applying this threshold simultaneously excludes weather situations irrelevant for our analysis, such as e.g. fronts, as those are associated with high- and mid-level clouds. Subjective assessment based on satellite imagery, webcams, visibility and cloud base height measurements show that with a threshold of $C L_{F L S}>0.7$ we can effectively detect FLS patches larger than a few kilometers during winter months (Ehrler, 2018).

This simple approach does not enable differentiation between stratiform and cumuliform clouds nor between ground-touching and elevated clouds, in contrast to the approaches presented by Bendix et al. (2005); Cermak and Bendix (2011); Egli et al. (2018). However, it fits our requirements as it is available with a high temporal resolution and applicable both during the day and at night.

As a proof of concept, Figure 3 shows the mean $C L_{F L S}$ between November 2016 and February 2017. The areas with high values for $C L_{F L S}$ correspond well to previous FLS-maps as e.g. drawn by Wanner (1979).

In the current study, we employ the presented FLS verification procedure to detect systematic forecast errors for the Swiss Plateau region and choose a represen- 
tative case study. In future studies, this FLS validation approach can be employed to easily evaluate the overall performance of model adaptations and potential improvements of FLS forecasts over all FLS cases of a season beyond single case studies.

\subsection{Visual comparison with satellite imagery}

For the case study, more details are discernible when satellite observations are compared visually with model output. During daytime, we use High-Resolution Visible Fog RGB images ${ }^{1}$ which have a high-resolution and allow for excellent differentiation between snow and FLS. During nighttime, Night Microphysics RGB images ${ }^{2}$ are employed. To detect the cloud base altitude at single locations, we use a LUFFT CHM15k ceilometer at Payerne (PAY) and a Vaisala CL31 ceilometer at Zürich airport $(\mathrm{ZRH})$.

\section{Methodology}

\subsection{Model description: COSMO-1}

$\mathrm{COSMO}^{3}$ is a regional weather prediction and climate model used at many national weather services and universities. The COSMO model solves non-hydrostatic, fully compressible hydro-thermodynamical equations using finite difference methods on an Arakawa C-grid (Arakawa and Lamb, 1977; Steppeler et al., 2003; Förstner and Doms, 2004). It is discretised on a rotated latitude longitude grid with a terrainfollowing smooth level vertical (SLEVE) coordinate (Schär et al., 2002; Leuenberger et al., 2010). The configuration used in this study, COSMO-1, closely follows the operational configuration of MeteoSwiss running at a horizontal grid spacing of $1.1 \mathrm{~km}$. This setup comprises $1158 \times 774$ grid cells and 80 model levels, the lowest model half-level is located at $10 \mathrm{~m}$ above the ground, and 24 levels lie in the first $1000 \mathrm{~m}$ above ground. The height above which the topographic signature in the SLEVE coordinates has decayed completely (i.e. the vertical levels are flat), $h_{\text {flat, }}$ is set at $11,357 \mathrm{~m}$ asl. The corresponding decay constants for large-scale and small-scale

\footnotetext{
${ }^{1}$ www.eumetrain.org/resources/MSG_HRVfogRGB_pink_cloud.html

${ }^{2}$ www.eumetrain.org/resources/MSG_nightmicro_green_cloud.html

${ }^{3}$ www.cosmo-model.org
} 
orographic features are set at 10,000 m and $3300 \mathrm{~m}$, respectively. The model orography (Fig. 2) is derived from the ASTER Global Digital Elevation Map, the horizontal grid spacing is about $30 \mathrm{~m}$ at the Equator. Land use data stem from the high-resolution GLOBCOVER dataset $(\Delta x=300 \mathrm{~m})$. Soil data are retrieved from the Harmonised World Soil Database ( $\Delta x=1 \mathrm{~km})$.

A fifth-order advection scheme is used for wind velocity, temperature and pressure in the horizontal dimension while in the vertical, a second-order implicit CrankNicholson scheme is employed (Baldauf et al., 2011). The prognostic variables are integrated forward in time employing a two-timelevel horizontally explicit, vertically implicit time-splitting scheme with a third-order Runge-Kutta discretisation with a time-step of $\Delta t=10 \mathrm{~s}$ (Klemp and Wilhelmson, 1978; Wicker and Skamarock, 2002). A second-order positive-definite advection scheme with directional-splitting (Bott, 1989; Schneider and Bott, 2014) is used for the advection of the moist quantities: Water vapour, cloud water, cloud ice, rain, snow, and graupel. TERRA-ML, a multi-layer soil model comprising eight soil levels, provides the lower boundary for COSMO (Heise et al., 2006). The Earth surface is coupled to the first model level via a turbulent kinetic energy (TKE)-based surface transfer scheme (Baldauf et al., 2011).

The turbulence closure only considers vertical processes, as is the case for most operational NWP models. The turbulent flux of a scalar quantity is estimated via K-theory, relating the subgrid-scale flux to the product of the gradient of the quantity and a turbulent diffusion coefficient. Vertical turbulent diffusion coefficients for heat (applied to temperature and the moisture variables) and momentum are calculated with a prognostic TKE-based 1.5-order scheme (Raschendorfer, 2001) with a level 2.5 closure following Mellor and Yamada (Mellor and Yamada, 1974, 1982). To prevent the total decay of turbulence in very stable situations, a minimum vertical turbulent diffusion coefficient $\left(0.4 \mathrm{~m}^{2} / \mathrm{s}\right.$ in our setup) is applied (Buzzi, 2008). Subgrid-scale cloudiness is diagnosed by an empirical function depending on relative humidity and altitude (Sommeria and Deardorff, 1977). See Buzzi et al. (2011) for a more detailed description of the turbulence parameterisation and the computation of the stability functions. A single-moment bulk cloud-microphysics scheme with six categories (water vapour, cloud water, cloud ice, rain, snow, and graupel) is used (Reinhardt and Seifert, 2006). Radiative processes interacting with both, 
grid- and subgrid-scale clouds are described with a delta-two-stream approach after Ritter and Geleyn (1992). The convection parameterisation is turned off.

COSMO-1 is a limited area model which spans the full Alpine region and closer surroundings (Fig. 2). Switzerland occupies approximately $4 \%$ of the total computational domain of COSMO-1 and is located close to the centre of the domain. The necessary boundary conditions are derived from the European Centre for MediumRange Weather Forcasts (ECMWF) Integrated Forecasting System (IFS) HRES ${ }^{4}$ forecast data. A realistic initial model state at the beginning of each forecast-hereafter referred to as âĂlJmodel analysisâĂí-is obtained from a continuous observation assimilation cycle employing a nudging algorithm (Schraff and Hess, 2012). For COSMO-1, horizontal winds, surface pressure, temperature and humidity from radiosoundings, surface observations, and aircrafts are assimilated.

We perform numerical simulations with the COSMO model version 5.0 adapted to run on graphics processing unit accelerated compute clusters.

The contributions of each model process to the total tendencies of temperature and moisture are retrieved using the COSMO budget-diagnosis tool, developed by Langhans et al. (2012).

Lagrangian backward trajectories are calculated employing an initial-coordinates technique (Gheusi and Stein, 2002) by implementing three additional passive tracers which are initialised with uniform zonal, meridional and vertical gradients, respectively, and experience advection as well as turbulent mixing.

\subsection{Case description: December 22-26, 2017}

The Swiss Plateau was covered by persistent FLS on the days around Christmas Eve 2017. Extensive FLS formed towards the end of December 22 and finally dissipated during December 26. Figure 4 shows a weather reanalysis map featuring a strong pressure ridge over central Europe, which promoted generally clear-sky conditions. On a smaller spatial scale, Figure 5 shows how extensive FLS covered the entire Swiss Plateau and extended deeply into adjacent Alpine valleys on December 24, around 1030 UTC (the FLS extent was comparable on all days, but the MODIS Terra satellite image was clearest on that day). Forecasters repeatedly reported that forecasts from various models (COSMO, Global Forecast System, as well as ECMWF-

\footnotetext{
${ }^{4}$ https://www.ecmwf.int/en/forecasts/datasets/set-i
} 
HRES) underestimated the FLS layer, most prominently on December 25 . As will be shown in Section 5.1, COSMO-1 has a systematic tendency to underestimate the occurrence of FLS. The FLS event during the December 22-26 period was archetypical for this behaviour and was selected as a case study. In this study, we will focus on the COSMO-1 simulation initialised on December 25, 2017, 0000 UTC for detailed analysis and sensitivity experiments.

\section{Results and Discussion}

\subsection{Seasonal verification with satellite imagery}

In the following, we present an evaluation of COSMO-1 FLS forecasts between November 2016 and February 2017. We restrict this analysis to days where at least $20 \%$ of the Swiss Plateau was covered by FLS according to satellite observations.

Figure 6 shows the diurnal cycle of median FLS fraction every three hours as detected by satellite (dark) vs. 12-hour model forecasts of COSMO-1 (light). FLS occurrence peaks towards the end of the night-before solar radiation can act to dissipate the clouds-and reaches a minimum at noon. COSMO-1 significantly underestimates the extent of FLS at any time of day (paired sample $t$-tests: $p<0.01$ for each hour of day).

Figure 7 shows a box and whiskers plot of the relative (with respect to observations) cloud fraction bias, $B_{C F}$, for leadtimes of $0,3,6,9$ and 12 hours. COSMO- 1 underestimates the extent of FLS for all leadtimes. On average, the extent of FLS is underestimated by about $31 \%$ at analysis time. This underestimation becomes more severe with increasing leadtime: After 12 hours of model simulation, COSMO-1 generally misses $70 \%$ of the observed FLS. To summarise, the negative bias regarding FLS extent is especially severe at longer leadtimes, as COSMO-1 dissipates FLS too fast.

\subsection{Case study: Comparison with observations}

To investigate the reasons for this bias in the model, we focus on a case representative for the too strong dissipation of FLS by the model. Figure 8 compares the FLS extent as observed by satellite with the COSMO-1 forecast issued on December 25, 
2017, 0000 UTC for +0 hours, +6 hours, and +12 hours. Overall, the model analysis captures the cloud extent fairly well. COSMO-1 however gradually dissipates the FLS clouds until they have fully disappeared by midday, while in reality the Swiss Plateau remained covered with FLS for the full day.

The radio sounding issued at Payerne (Fig. 2) depicts a low stratus layer with a thickness of nearly $300 \mathrm{~m}$ (Fig. 9, left panel). At midnight, ceilometer measurements indicate a cloud base altitude of $171 \mathrm{~m}$ (660 m asl) at PAY, and $165 \mathrm{~m}$ (591 m asl) at ZRH. The cloud top-confined by a temperature inversion-is located around $900 \mathrm{~m}$ asl and decreases in height towards $850 \mathrm{~m}$ asl at noon (Fig. 9, right panel). The simulated temperature inversion height at analysis time (Fig. 9a) roughly has the correct height but is about $1.5 \mathrm{~K}$ too warm while the simulated surface temperature is almost $0.5 \mathrm{~K}$ too cold. This leads to a rather stably stratified boundary layer in contrast to the observed well-mixed layer. After 12 hours of model simulation, at midday, the modelled inversion has sunken towards the ground and has eroded almost completely (Fig. 9b). As a consequence of the missing FLS cover in the model, the surface experiences more solar heating and thereupon is nearly $2 \mathrm{~K}$ warmer than observed.

At initialisation time, the specific humidity profile of the model corresponds well with the observation, except for a slightly too uniform profile up to the inversion height (Fig. 9c). At noon, COSMO-1 exhibits a linearly decreasing specific humidity profile (Fig. 9d). Above the modelled temperature inversion, the moist air seems to have been mixed with the originally drier air above the inversion. A limited moist residual remains below the inversion. Thus, compared to the radiosounding, the model overestimates the specific humidity below $1000 \mathrm{~m}$ asl and underestimates it above.

At midnight, the radiosounding exhibits a low-level jet (maximum wind speed of $5 \mathrm{~m} / \mathrm{s}$ ) at the centre of the stratus and low wind speeds ( $<2 \mathrm{~m} / \mathrm{s}$ ) below (Fig. $9 \mathrm{e}$ ). COSMO-1 places the low-level jet about $100 \mathrm{~m}$ too low. Another wind speed maximum occurs right above the stratus $(9 \mathrm{~m} / \mathrm{s})$ which is somewhat underestimated by the model. Although FLS formation is favourable in calm conditions, these high wind speeds at a mature stage are not exceptional: Ramelli et al. (2020) reported wind speeds around $10 \mathrm{~m} / \mathrm{s}$ within the cloud layer for a different FLS case over the Swiss Plateau. At midday (Fig. 9f), a general increase in wind speeds up to $2000 \mathrm{~m}$ 
asl is present which also penetrates the stratus. The model underestimates the wind speed between $1000 \mathrm{~m}$ asl and $2000 \mathrm{~m}$ asl, however, the wind speed at the stratus top height is correct (about $6 \mathrm{~m} / \mathrm{s}$ ). Only that, by this time, the model has already dissipated the stratus and all that is left is confined in a de-coupled layer close to the surface. Standard radiosonde observations do not include the liquid water content (LWC). LWC could be obtained with measurement devices such as a tetherd balloon (Seidel et al., 2016; Ramelli et al., 2020), a combination of lidar (Light Detection and Ranging) and microwave radiometer (Navas-Guzmán et al., 2014), or a profiling microwave radiometer (Gultepe et al., 2014).

\subsection{Evolution of cloudy vertical profile}

It is striking, how much of the FLS the model dissipates already during the night between 0000 UTC and 0600 UTC (Fig. 8). We conduct a detailed analysis of the first simulation hours to gain insight into the driving processes for this behaviour.

Figure 10 shows the development of the vertical profiles of the LWC, liquid water potential temperature (LWPT, for calculation see Betts, 1973), and specific humidity for the first five simulation hours at ZRH (Fig. 2, the vertical wind is shown in Fig. A.2 in the Appendix). The maximum LWC $(0.54 \mathrm{~g} / \mathrm{kg}$ at $875 \mathrm{~m}$ asl, at analysis time) is located near the cloud top, as expected for an optically thick stratus cloud (Hoffmann and Roth, 1989). With increasing leadtime, the cloud layer gradually dries out and becomes thinner until it has dissipated almost completely after only 3 hours at 0300 UTC and thus even before sunrise (at around 0700 UTC). It is noteworthy that the lowering of the cloud top is much more substantial than the lifting of the cloud base.

The cloud top lowers along with the extent of the well-mixed layer, identified as the layer with constant LWPT. Over time, the LWPT at $1200 \mathrm{~m}$ asl remains constant (around $290 \mathrm{~K}$ ), as well as the overall minimum LWPT (around $276 \mathrm{~K}$ ). But the elevational extent of the well-mixed layer decreases from $950 \mathrm{~m}$ asl to about $600 \mathrm{~m}$ asl during five forecast hours from 0000 UTC to 0500 UTC. More precisely, the sharp increase in LWPT above the stratus ( $11 \mathrm{~K}$ between $920 \mathrm{~m}$ asl and $1090 \mathrm{~m}$ asl) found at 0000 UTC gets dispersed in the vertical: At 0500 UTC, the increase in LWPT occurs already above $650 \mathrm{~m}$ asl.

Specific humidity decreases with height, from about $3.9 \mathrm{~g} / \mathrm{kg}$ at the surface to 
about $3.5 \mathrm{~g} / \mathrm{kg}$ near the cloud top at 0000 UTC. One would expect that the evaporated cloud water would lead to an increase in specific humidity, however, the latter is decreasing throughout the full lower atmosphere by about $0.5 \mathrm{~g} / \mathrm{kg}$ during this time.

\subsection{Sensitivity experiments}

In the following, we present a series of sensitivity experiments in order to identify the process that shows the highest potential for improving FLS forecasts. All sensitivity experiments are based on experiments which had been shown to improve FLS forecasts in literature.

\subsubsection{Sensitivity to microphysics parameterisation}

Recent studies suggest two different approaches to improve FLS forecasts by making changes to the microphysics parameterisation. First, Szintai et al. (2015) have found that, in cases with negative temperatures at the surface, excessive dissipation of FLS in the AROME model could be improved by increasing the threshold for autoconversion in the microphysics parameterisation and thereby decreasing the positive bias in solid precipitation. COSMO-1 does not produce any kind of precipitation for the case study, so we clearly have a different problem to address.

We have run a simulation where the microphysics parameterisation is turned off and only saturation adjustment is active, which restores the thermodynamic balance between water vapour and liquid water after the advection of the prognostic variables. The results can not be distinguished from a simulation with full microphysics, which leads to the conclusion, that the saturation adjustment is the dominating cloud microphysical process in the current setup.

The evolution of the fog droplet number concentration-which is not considered in COSMO-1-are known to substantially affect FLS simulations (Bergot et al., 2007; Maronga and Bosveld, 2017; Mazoyer et al., 2017; Boutle et al., 2018). In our reference simulation we employed the single-moment bulk cloud-microphysics scheme used in the operational setup of COSMO-1. Additionally we tested the impact of the two-moment scheme PArameterised FOG (=PAFOG) developed by Bott and Trautmann (2002) which has been shown to have beneficial effects on FLS forecasting 
in studies by Gultepe et al. (2006); Masbou (2008); Müller et al. (2010); Hacker (2016). A comparison of Figure 11a (PAFOG two-moment microphysics scheme) with $b$ (one-moment microphysics scheme) demonstrates however, that, for our case, the FLS underestimation becomes even more severe. This possibly is a consequence of the sedimentation of cloud droplets which is neglected in the COSMO single-moment microphysics. To summarise, while we see some sensitivity to the evolution of the FLS layer with respect to the treatment of cloud water, the microphysics parameterisation scheme is not the dominant model process leading to a premature dissipation of the FLS layer.

\subsubsection{Sensitivity to minimal vertical mixing coefficients}

Several studies have highlighted the need for reducing the minimum turbulent mixing coefficients for stable boundary layer cases (Buzzi, 2008; Cerenzia et al., 2014; Possner et al., 2014; Hacker, 2016), in order to reduce mixing across the inversion. When the lower bound imposed on the turbulent mixing coefficients for heat and momentum is reduced from $0.4 \mathrm{~m}^{2} / \mathrm{s}$ to $0.01 \mathrm{~m}^{2} / \mathrm{s}$, FLS at 0900 UTC is indeed slightly more extensive compared to the reference simulation, see Figure $11 \mathrm{c}$ compared to b. However, for our case, this measure does not prevent the erroneous FLS dissipation, it merely delays it by approximately 1 hour.

\subsubsection{Sensitivity to horizontal and vertical grid spacing}

Adding 32 vertical levels in the first $2000 \mathrm{~m}$ (amounting to a total of 112 instead of 80 vertical levels) showed very little to no improvement at all to the modelled low cloud extent and cloud water content (not shown). This corresponds well to findings of Philip et al. (2016); they showed that, for comparable grid dimensions, increasing the number of vertical levels from 60 to 156 positively affected the fog formation phase (which, in our case, had occurred three days prior to the simulation under investigation) but not the mature and dissipation phases.

When the horizontal grid spacing $\Delta x$ is decreased from $1.1 \mathrm{~km}$ to $550 \mathrm{~m}$ (all other model parameters are kept constant except for the timestep which is decreased to $\Delta t=5 \mathrm{~s}$ ), the model maintains a slightly more extensive FLS layer (Fig. 12e vs g). Comparison with simulations using $\Delta x=4.4 \mathrm{~km}(\Delta t=40 \mathrm{~s})$ and $2.2 \mathrm{~km}(\Delta t=20 \mathrm{~s})$, 
see Fig. 12a and c, further illustrates that small grid spacing is beneficial for FLS modelling as the extent of FLS becomes larger with decreasing grid spacing.

This may seem to contradict the findings of Boutle et al. (2016) who argued that the representation of small-scale orographic features acts to dissipate fog by introducing additional mixing. They presented a case study where the simulation at coarser grid spacing $(1.5 \mathrm{~km})$ produced too widespread fog which was reduced when changing to smaller grid spacing (333 m). However, we consider their results as being applicable to our case as well. Figures $12 \mathrm{~d}, \mathrm{f}$ and $\mathrm{h}$ depict the FLS extent modelled with COSMO-1 at $\Delta x=2.2 \mathrm{~km}, 1.1 \mathrm{~km}$ and $550 \mathrm{~m}$, but the orography in these setups (hereafter referred to as "low-resolution") are derived from linear interpolation from the orography used for the $4.4 \mathrm{~km}$ simulation and discrete external parameters such as soil type and land fraction are interpolated using nearestneighbour interpolation (similar procedure as in Panosetti et al., 2019).

At the same grid spacing, the low-resolution simulations show noticeably more widespread FLS than their high-resolution counterparts. Even more, the low-resolution simulations at $\Delta x=2.2 \mathrm{~km}, 1.1 \mathrm{~km}$, and $550 \mathrm{~m}$ exhibit higher LWC and higher cloud tops than any of the high-resolution simulations or the experiment with reduced minimum turbulent diffusion coefficients (Fig. 12b) Nevertheless, any forecast model setup dissipates FLS too quickly and eventually forecasts clear-sky conditions for December 25, 2017.

The timesteps are chosen such to ensure a constant Courant-Friedrichs-Lewy criterion. Using $1.1 \mathrm{~km}$ horizontal grid spacing and $\Delta t=5 \mathrm{~s}$ (instead of $10 \mathrm{~s}$ ) does not show significant differences, similar as in Panosetti et al. (2019, not shown).

\subsection{Moisture budget analysis}

While the model's rapid dissipation of the FLS layer has shown some sensitivity to minimal vertical turbulent diffusion coefficients and horizontal resolution, they do not seem to address the root cause.

Figure 13 shows a budget analysis of the evolution of the LWC profile at ZRH averaged over the period from 0045 UTC to 0100 UTC (similar to the analyses described in Kim et al., 2020). During these 15 min the cloud top is lowered by about $50 \mathrm{~m}$ (Fig. 13a). Between $640 \mathrm{~m}$ asl and $840 \mathrm{~m}$ asl, a slight increase in LWC occurs. However, the loss at the top is more dominant; in total about $15 \%$ of the cloud 
water in this column is lost: The LWP decreases from $0.063 \mathrm{~kg} / \mathrm{m}^{2}$ to $0.053 \mathrm{~kg} / \mathrm{m}^{2}$.

Three different model processes affect the LWC (Fig. 13b): Advection $\left(\Delta q c_{a d v}\right.$, blue), turbulent mixing ( $\Delta q c_{\text {turb }}$, yellow) and evaporation resp. condensation $\left(\Delta q c_{\text {mic }}\right.$, green). The largest tendencies occur at the (lowered) cloud top, at around $840 \mathrm{~m}$ asl. A LWC gain of almost $10 \mathrm{~g} \mathrm{~kg}^{-1} \mathrm{~h}^{-1}$ due to condensation of water vapour, driven by radiative cooling (e.g. Wærsted et al., 2017), is balanced by a loss due to turbulent mixing which redistributes the LWC peak. The combined effect of these two processes is illustrated with the dashed light green line representing $\Delta q c_{\text {turb }}+\Delta q c_{\text {mic }}$.

The overall total tendency ( $\Delta q c_{\text {tot }}$, black) at around $840 \mathrm{~m}$ asl is close to $0 \mathrm{~g} \mathrm{~kg}^{-1} \mathrm{~h}^{-1}$. Below $780 \mathrm{~m}$, asl turbulent mixing increases the LWC by up to $4 \mathrm{~g} \mathrm{~kg}^{-1} \mathrm{~h}^{-1}$ while about the same amount of cloud water is evaporated, resulting in almost vanishing $\Delta q c_{\text {tot }}$, which is to be expected for a neutrally stratified fog layer.

Overall, $\Delta q c_{\text {turb }}+\Delta q c_{\text {mic }}$ is close to zero at all elevations. Also $\Delta q c_{\text {tot }}$ is mostly zero, except at around $880 \mathrm{~m}$ asl. At this elevation, processes associated to the model's advection scheme lead to a loss in LWC of about $-1 \mathrm{~g} \mathrm{~kg}^{-1} \mathrm{~h}^{-1}$ which is sufficient to completely remove the cloud water in this region within only $15 \mathrm{~min}$.

Corresponding to a high-pressure dominated synoptic setting one might suspect excessive subsidence to be the driver for LWC loss at the cloud top. Figure 13c illustrates the vertical and horizontal components of the advection tendency $\Delta q c_{a d v}$. Since the advection operators are implemented on the terrain-following grid, these components are approximated using an estimate of the vertical advection tendency employing a centred-difference scheme. The horizontal tendency is then computed as the residual with respect to the total $\Delta q c_{a d v}$. Although this estimation is not perfect, the results clearly indicate that the horizontal advection is the dominant process.

To summarise, we find that, below the cloud top, the model maintains the expected balance of turbulent mixing and saturation adjustment of a neutrally stratified, saturated FLS layer. The FLS dissipation occurs near the cloud top and is related to the advection scheme of the model. While the above analysis has focused on a single grid cell, these findings are valid for the majority of grid cells with FLS and different lead times as well. Furthermore, the dominant negative horizontal advection tendencies near the cloud top were also found for a fog case on December 14, 2016. 


\subsection{Airmass tracking}

We address the question whether the negative advection tendencies are caused by advection of dry air from outside the stratus using Lagrangian backward trajectories following the approach of Gheusi and Stein (2002).

Figure 14 shows the 3-hour backwards trajectories arriving at PAY, Oftringen (OFT), and Lake Konstanz (LAK) at 0300 UTC at either $800 \mathrm{~m}$ asl (hereafter referred to as lower trajectories) or $1000 \mathrm{~m}$ asl (upper trajectories). The locations of PAY, OFT and LAK are indicated in Figure 2. Air parcel positions are calculated every 15 min (dots) and their colouring indicates the total specific humidity (sum of liquid water and water vapour). All trajectories depict a uniform picture: A dominant southwesterly flow situation throughout the Swiss Plateau and no significant vertical wind shear at these heights. Along the upper LAK-trajectory, the wind displaces the air by about $95 \mathrm{~km}$ during these 3 hours and by about $73 \mathrm{~km}$ along the lower trajectory. The vertical displacement is on the order of tens of meters (not shown). The upper trajectory, which is above the FLS, experiences an increase in total humidity from $2.5 \mathrm{~g} / \mathrm{kg}$ at 0000 UTC to almost $3 \mathrm{~g} / \mathrm{kg}$ at 0300 UTC. In contrast, for the lower trajectory, starting at the centre of the stratus, the total humidity decreases from $4.25 \mathrm{~g} / \mathrm{kg}$ to $3.5 \mathrm{~g} / \mathrm{kg}$.

The trajectory analysis corroborates the fact, that the FLS over the Swiss Plateau for this case study does not dissipate because of the advection of a drier airmass from the southwest. The loss in total humidity apparent in the lower trajectories and simultaneous increase in total humidity in the upper trajectories can only be explained by a vertical mixing process along the way.

\subsection{Numerical uncertainty related to boundary layer diffusivity}

Combining the facts that the sensitivity experiments in Sections 5.4.1-5.4.3 have not been able to identify the main concerns to be addressed, and that the analyses in Sections 5.5 and 5.6 have revealed excessive mixing at the cloud top related to the advection scheme, this points towards numerical diffusion to be the key component requiring attention.

Horizontal diffusion along model surfaces is known to promote unrealistic (vertical) mixing of adjacent cells which exhibit large differences in temperature and hu- 
midity up and down mountain slopes (Wilson and Fovell, 2016). In our model setup, a fourth-order hyper-diffusion operator along model levels is applied in the boundary zone where the prognostic variables are relaxed against the driving model. In the centre of the computational domain however, no numerical damping is activated to stabilise the model. Nevertheless, the Bott advection scheme (Bott, 1989) used to transport moisture variables exhibits a certain amount of implicit diffusivity, especially along strong gradients in the fields that are being transported. Also, the Bott advection scheme is a one-dimensional advection scheme and Strang-splitting along the three dimensions is used to implement the fully three-dimensional advection operator (Strang, 1968). This means that, for a purely horizontal flow in presence of orography, the vertical advection scheme has to compensate the advection along the sloping coordinate surfaces (using contravariant advection velocities).

Flat, low-elevation regions are scarce in Switzerland. While the Swiss Plateau may seem flat as compared to the surrounding mountain ranges (Jura, Alps), variations in surface elevation easily amount to few hundreds of meters even on the Swiss Plateau. In order to investigate the sensitivity of the FLS dissipation to the implicit diffusion of the advection scheme in the presence of terrain-following coordinates, we present a sensitivity experiment where $h_{\text {flat }}$ lies below the cloud top (850 $\mathrm{m}$ asl instead of $11,357 \mathrm{~m}$ asl). The computational domain for this experiment had to be confined to a nested subdomain of $25 \times 25 \mathrm{~km}$ northeast of ZRH, since $h_{\text {flat }}$ always has to be some at distance above the mountain tops. For this reduced domain, $850 \mathrm{~m}$ is the lowest value for $h_{\text {flat }}$ for which a simulation was possible. The scale heights $s_{1}$ and $s_{2}$ of the SLEVE coordinate (cf. Schär et al., 2002) were set to $840 \mathrm{~m}$ asl and $830 \mathrm{~m}$ asl, respectively. Due to the small horizontal domain, we can only analyse the results for short leadtimes. With a horizontal wind speed of 5-10 m/s, we expect results to be contaminated by boundary effects after approximately one hour of simulation time.

Figure 15 shows the south-north cross-section of the elevation of the model levels together with the cloud layer for both setups. For $h_{\text {flat }}=11,357 \mathrm{~m}$ asl, the orographic signature is clearly visible throughout the lower atmosphere at typical FLS cloud top heights while for $h_{\text {flat }}=850 \mathrm{~m}$ asl, the vertical levels near the cloud top are quasi-horizontal and do not cut through the cloud top. As a consequence of the lowering of $h_{\text {flat }}$, the levels become squeezed together close to the ground; for $h_{\text {flat }}$ 
$=850 \mathrm{~m}$ asl the minimal thickness is $7.71 \mathrm{~m}$ as opposed to $19.65 \mathrm{~m}$. Furthermore, as the total number of vertical levels is kept constant, the level thickness makes a jump above $850 \mathrm{~m}$ asl. However, as already stated above, our case exhibited no sensitivity to decreased vertical layer thickness.

Lowering $h_{\text {flat }}$ directly affects the LWC, especially near the cloud top. Figure $16 a$ compares the vertical LWC-profiles after 1 hour of simulation above Andelfingen (AND, see Fig. 2), which is located close to the centre of the reduced computational domain. The cloud top is clearly better maintained (around $900 \mathrm{~m}$ asl) in the experiment with lower $h_{\text {flat }}$. Within only one hour, the cloud top height and maximum LWC for the two setups differ by more than $30 \mathrm{~m}$ and $0.05 \mathrm{~g} / \mathrm{kg}$, respectively.

A comparison of Figure $16 \mathrm{~b}\left(h_{\text {flat }}=11,357 \mathrm{~m}\right.$ asl $)$ and $\mathrm{c}\left(h_{\text {flat }}=850 \mathrm{~m}\right.$ asl $)$ illustrates how these differences in the LWC-profiles indeed correlate with reduced negative advection tendencies in the simulation with lower $h_{\text {flat }}$. (To allow for comparison, the tendencies are averaged for the first simulation hour.) Negative advection tendencies are still apparent but much reduced, especially near the cloud top; around $-0.3 \mathrm{~g} \mathrm{~kg}^{-1} \mathrm{~h}^{-1}$ as opposed to $-0.72 \mathrm{~g} \mathrm{~kg}^{-1} \mathrm{~h}^{-1}$ in the reference simulation. The result is a more persistent FLS layer in the experiment with flat model levels near the cloud top. This finding supports the hypothesis that the implicit diffusion of the advection scheme contributes significantly to excessive vertical mixing.

It should be noted that the lowering of $h_{\text {flat }}$ is possible for a small model domain without significant topography, but not for typical computational domains of operational NWP models. Furthermore, while in our case study the cloud top was located at a height of $900 \mathrm{~m}$ asl, FLS tops can be anywhere from only a few meters above ground to almost $2000 \mathrm{~m}$ asl. Thus, lowering $h_{\text {flat }}$ is not generally applicable, but can serve as a tool to assess the sensitivity of FLS dissipation due to the advection scheme's inherent implicit diffusion.

\section{Summary and Conclusions}

Forecasting fog and low stratus (FLS) is challenging even with state-of-the-art highresolution NWP models. In this article, we investigated the key model processes for predicting wintertime FLS forecasts in complex terrain on the Swiss Plateau. We presented a novel method for evaluating forecasted FLS extent based on satellite 
imagery. We showed that COSMO-1, the operational high-resolution NWP model employed at MeteoSwiss, substantially underestimated FLS compared to the satellite product from November 2016 to February 2017. The negative bias of FLS extent increased with increasing leadtime; generally, the model dissipated FLS clouds too rapidly.

We selected a representative case, the COSMO-1 forecast for December 25, 2017, that we analysed in detail. On that day, COSMO-1 had erroneously dissipated extensive FLS covering the Swiss Plateau and adjacent Alpine valleys within a few hours. An interesting aspect worth noting was that large regions became cloud-free already before sunrise.

Comparison with observations revealed that the FLS extent as well as the height of the cloud top confined by a strong temperature inversion were well-captured in the analysis that served as a starting point of the forecast. Throughout the first 4-5 forecast hours, the model exhibited a substantial loss of liquid water content (LWC) associated with a sinking of the cloud top and a degradation of the temperature inversion.

For the representative case study several sensitivity experiments were carried out-each of them had been reported to improve FLS simulations in various earlier studies-to investigate which model processes are relevant for improving FLS forecasts in complex terrain. Six conclusions can be drawn: (1) The saturation adjustment was the dominant cloud microphysical process in the current setup of COSMO-1. (2) The introduction of a two-moment microphysics scheme (PAFOG, developed by Bott and Trautmann, 2002) led to even faster FLS dissipation, probably due to removal of larger cloud droplet via sedimentation, which was not taken into account by the standard microphysics scheme of COSMO. (3) Increasing the vertical resolution of the model did not produce significantly better results, indicating that the number of vertical levels is not the key problem in predicting FLS with COSMO1. (4) Decreasing the lower bound for turbulent mixing coefficients and decreasing horizontal grid spacing were the only applied measures which led to improvements with respect to the FLS extent and FLS persistence. However, the dissipation of FLS could not be prevented but only delayed. This potential improvement, however, comes at the expense that a lower bound for the turbulent mixing coefficient is known to lead to instabilities in the turbulence scheme for certain meteorological 
situations (Buzzi, 2008), and a doubling of resolution is too costly to introduce in an operational forecasting system. (5) A decrease in horizontal grid spacing while retaining the coarse resolution orography and external parameters (such as landuse and soil-type) led to a more extensive FLS layer as compared to experiments in which both the resolution as well as the associated orography and external parameters were modified. (6) An analysis of the LWC budget revealed that negative development rates near the cloud top can be attributed primarily to horizontal advection. A trajectory analysis indicated that this drying is not associated with the advection of a dry airmass from outside the FLS region, but must be associated with a numerical vertical mixing process inherent to the advection scheme.

COSMO-1 employs a vertical terrain-following coordinate system, and the prevalent horizontal winds both within and above the FLS layer need to cross multiple model levels due to the moderate orography present on the Swiss Plateau. An experiment in which we forced the vertical levels to become quasi-horizontal at the cloud top resulted in significantly reduced negative advection tendencies and an improved LWC profile. We conclude that the implicit numerical mixing of the advection scheme in terrain-following coordinates is the primary cause for the rapid dissipation of the FLS layer in our case study. This interpretation is consistent with the result that forecasts with a smooth orography generate more extensive FLS clouds: Vertical levels exhibiting less steep gradients suffer less from implicit numerical diffusion than what is observed with steep gradients.

Furthermore, also stratocumulus clouds are suspected to suffer from numerical diffusion near sharp inversions (Lock, 2004). To improve numerical simulations of stratiform clouds in the boundary layer we suggest that future research should focus on the quantification of the implicit numerical diffusion of advection in terrainfollowing coordinates.

\section{Acknowledgements}

This project was supported by ETH Research Grant ETH-17 16-2 and by the Federal Office of Meteorology and Climate MeteoSwiss. We thank André Walser, Jean-Marie Bettems, Guy de Morsier, Daniel Leuenberger, Petra Baumann and Katherine Osterried for their technical assistance for running simulations with the COSMO model. 
We thank Ulrich Hamann providing satellite imagery and Maxime Hervo for the ceilometer data. We thank the Swiss National Supercomputing Centre (CSCS) for providing the computational resources. We further thank lan Boutle, Andreas Bott and Maike Hacker for fruitful discussions about fog and low stratus modelling. We would also like to thank Ismail Gultepe and one additional anonymous reviewer for their comments on the manuscript. The authors declare no conflict of interests. 


\section{References}

Andersen, H. and Cermak, J. (2018). First fully diurnal fog and low cloud satellite detection reveals life cycle in the Namib. Atmospheric Measurement Techniques, 11(10):5461-5470.

Arakawa, A. and Lamb, V. R. (1977). Computational design of the basic dynamical processes of the UCLA general circulation model. General Circulation Models of the Atmosphere, 17(Supplement C):173-265.

Bachmann, M. and Bendix, J. (1993). Nebel im Alpenraum. Bonner Geogr. Abh, 86:113-187.

Baldauf, M., Seifert, A., Förstner, J., Majewski, D., Raschendorfer, M., and Reinhardt, T. (2011). Operational convective-scale numerical weather prediction with the COSMO model: Description and sensitivities. Monthly Weather Review, 139(12):3887-3905.

Belo-Pereira, M. and Santos, J. (2016). A persistent wintertime fog episode at Lisbon airport (Portugal): performance of ECMWF and AROME models. Meteorological Applications, 23(3):353-370.

Bendix, J., Thies, B., Cermak, J., and Nauß, T. (2005). Ground fog detection from space based on MODIS daytime data-A feasibility study. Weather and Forecasting, 20(6):989-1005.

Bergot, T., Terradellas, E., Cuxart, J., Mira, A., Liechti, O., Mueller, M., and Nielsen, N. W. (2007). Intercomparison of single-column numerical models for the prediction of radiation fog. Journal of Applied Meteorology and Climatology, 46(4):504521.

Betts, A. (1973). Non-precipitating cumulus convection and its parameterization. Quarterly Journal of the Royal Meteorological Society, 99(419):178-196.

Bott, A. (1989). A positive definite advection scheme obtained by nonlinear renormalization of the advective fluxes. Monthly Weather Review, 117(5):1006-1016.

Bott, A. and Trautmann, T. (2002). PAFOG - A new efficient forecast model of radiation fog and low-level stratiform clouds. Atmospheric Research, 64(1-4):191-203. 
Boutle, I., Finnenkoetter, A., Lock, A., and Wells, H. (2016). The London Model: Forecasting fog at 333 m resolution. Quarterly Journal of the Royal Meteorological Society, 142(694):360-371.

Boutle, I., Price, J., Kudzotsa, I., Kokkola, H., and Romakkaniemi, S. (2018). Aerosolfog interaction and the transition to well-mixed radiation fog. Atmospheric Chemistry and Physics, 18(11):7827-7840.

Brown, R. and Roach, W. (1976). The physics of radiation fog: II-a numerical study. Quarterly Journal of the Royal Meteorological Society, 102(432):335-354.

Buhler, Y., Dammann, K., Flewin, J., Fowler, G., Müller, J., Rogers, C., and Williams, M. (2017). MSG level 1.5 image data format description. Technical Report 8, EUMETSAT.

Buzzi, M. (2008). Challenges in operational numerical weather prediction at high resolution in complex terrain. PhD thesis, ETH Zürich.

Buzzi, M., Rotach, M. W., Holtslag, M., and Holtslag, A. A. (2011). Evaluation of the cosmo-sc turbulence scheme in a shear-driven stable boundary layer. Meteorologische Zeitschrift, 20(3):335-350.

Cerenzia, I., Tampieri, F., and Tesini, M. S. (2014). Diagnosis of turbulence schema in stable atmospheric conditions and sensitivity tests. COSMO Newsletter, 14:1-11.

Cermak, J. (2018). Fog and low cloud frequency and properties from active-sensor satellite data. Remote Sensing, 10(8):1209.

Cermak, J. and Bendix, J. (2011). Detecting ground fog from space - a microphysicsbased approach. International Journal of Remote Sensing, 32(12):3345-3371.

Chachere, C. N. and Pu, Z. (2019). Numerical simulations of an inversion fog event in the salt lake valley during the MATERHORN-fog field campaign. Pure and Applied Geophysics, 176(5):2139-2164.

Courvoisier, H. W. (1976). Die Abhängigkeit der Sonnenscheindauer vom kleinräumigen Druckgradienten in den Niederungen bei winterlichen Inversionslagen. SMZ. 
Egli, S., Thies, B., and Bendix, J. (2018). A hybrid approach for fog retrieval based on a combination of satellite and ground truth data. Remote Sensing, 10(4):628.

Ehrler, A. (2018). A methodology for evaluating fog and low stratus forecasts with satellite data. Master's thesis, ETH Zürich.

Förstner, J. and Doms, G. (2004). Runge-Kutta time integration and high-order spatial discretization of advection-a new dynamical core for the LMK. COSMO Newsletter, 4:168-176.

Gheusi, F. and Stein, J. (2002). Lagrangian description of airflows using Eulerian passive tracers. Quarterly Journal of the Royal Meteorological Society: A journal of the atmospheric sciences, applied meteorology and physical oceanography, 128(579):337-360.

Gultepe, I., Fernando, H., Pardyjak, E., Hoch, S., Silver, Z., Creegan, E., Leo, L., Pu, Z., De Wekker, S., and Hang, C. (2016). An overview of the MATERHORN fog project: observations and predictability. Pure and Applied Geophysics, 173(9):2983-3010.

Gultepe, I., Kuhn, T., Pavolonis, M., Calvert, C., Gurka, J., Heymsfield, A. J., Liu, P., Zhou, B., Ware, R., Ferrier, B., Milbrandt, J., and Bernstein, B. (2014). Ice fog in Arctic during FRAM-Ice Fog Project: Aviation and nowcasting applications. Bulletin of the American Meteorological Society, 95(2):211-226.

Gultepe, I., Müller, M. D., and Boybeyi, Z. (2006). A new visibility parameterization for warm-fog applications in numerical weather prediction models. Journal of applied meteorology and climatology, 45(11):1469-1480.

Gultepe, I., Tardif, R., Michaelides, S., Cermak, J., Bott, A., Bendix, J., Müller, M., Pagowski, M., Hansen, B., Ellrod, G., Jacobs, W., Toth, G., and S.G., C. (2007). Fog research: A review of past achievements and future perspectives. Pure and Applied Geophysics, 164(6-7):1121-1159.

Gultepe, I., Zhou, B., Milbrandt, J., Bott, A., Li, Y., Heymsfield, A. J., Ferrier, B., Ware, R., Pavolonis, M., Kuhn, T., Gurka, J., Liu, P., and Cermak, J. (2015). A review on ice fog measurements and modeling. Atmospheric Research, 151:2-19. 
Hacker, M. (2016). COSMO-PAFOG: Dreidimensionale Nebelvorhersage mit dem hochaufgelÃüsten COSMO-Modell. Master's thesis, University of Bonn.

Heise, E., Ritter, B., Schrodin, R., and Wetterdienst, D. (2006). Operational implementation of the multilayer soil model. COSMO Technical Report, 9:20.

Hoffmann, H.-E. and Roth, R. (1989). Cloudphysical parameters in dependence on height above cloud base in different clouds. Meteorology and Atmospheric Physics, 41(4):247-254.

Key, J. R. and Schweiger, A. J. (1998). Tools for atmospheric radiative transfer: Streamer and FluxNet. Computers \& Geosciences, 24(5):443-451.

Kim, W., Yum, S. S., Hong, J., and Song, J. I. (2020). Improvement of fog simulation by the nudging of meteorological tower data in the WRF and PAFOG coupled model. Atmosphere, 11(3):311.

Klemm, O. and Lin, N. (2016). What causes observed fog trends: Air quality or climate change. Aerosol and Air Quality Research, 16(5):1131-1142.

Klemp, J. B. and Wilhelmson, R. B. (1978). The simulation of three-dimensional convective storm dynamics. Journal of the Atmospheric Sciences, 35(6):10701096.

Köhler, C., Steiner, A., Saint-Drenan, Y.-M., Ernst, D., Bergmann-Dick, A., Zirkelbach, M., Bouallègue, Z. B., Metzinger, I., and Ritter, B. (2017). Critical weather situations for renewable energies - Part B: Low stratus risk for solar power. Renewable Energy, 101:794-803.

Kulkarni, R., Jenamani, R. K., Pithani, P., Konwar, M., Nigam, N., and Ghude, S. D. (2019). Loss to aviation economy due to winter fog in New Delhi during the winter of 2011-2016. Atmosphere, 10(4):198.

Langhans, W., Fuhrer, O., and Schmidli, J. (2012). Description and application of a budget-diagnosis tool in COSMO. COSMO Newsletter, 12:43-51.

Leuenberger, D., Koller, M., Fuhrer, O., and Schär, C. (2010). A generalization of the SLEVE vertical coordinate. Monthly Weather Review, 138(9):3683-3689. 
Lock, A. (2004). The sensitivity of a GCM's marine stratocumulus to cloud-top entrainment. Quarterly Journal of the Royal Meteorological Society: A journal of the atmospheric sciences, applied meteorology and physical oceanography, 130(604):3323-3338.

Maronga, B. and Bosveld, F. (2017). Key parameters for the life cycle of nocturnal radiation fog: a comprehensive large-eddy simulation study. Quarterly Journal of the Royal Meteorological Society, 143(707):2463-2480.

Masbou, M. (2008). LM-PAFOG: A new three-dimentional fog forecast model with parametrised microphysics. PhD thesis, Université Blaise Pascal-ClermontFerrand II.

Mazoyer, M., Lac, C., Thouron, O., Bergot, T., Masson, V., and Musson-Genon, L. (2017). Large eddy simulation of radiation fog: Impact of dynamics on the fog life cycle. Atmospheric Chemistry and Physics, 17(21):13017.

Mellor, G. L. and Yamada, T. (1974). A hierarchy of turbulence closure models for planetary boundary layers. Journal of the Atmospheric Sciences, 31(7):17911806.

Mellor, G. L. and Yamada, T. (1982). Development of a turbulence closure model for geophysical fluid problems. Reviews of Geophysics, 20(4):851-875.

Müller, M. D., Masbou, M., and Bott, A. (2010). Three-dimensional fog forecasting in complex terrain. Quarterly Journal of the Royal Meteorological Society, 136(653):2189-2202.

Navas-Guzmán, F., Stähli, O., and Kämpfer, N. (2014). An integrated approach toward the incorporation of clouds in the temperature retrievals from microwave measurements. Atmospheric Measurement Techniques, 7(6):1619-1628.

Panosetti, D., Schlemmer, L., and Schär, C. (2019). Bulk and structural convergence at convection-resolving scales in real-case simulations of summertime moist convection over land. Quarterly Journal of the Royal Meteorological Society, 145(721):1427-1443. 
Philip, A., Bergot, T., Bouteloup, Y., and Bouyssel, F. (2016). The impact of vertical resolution on fog forecasting in the kilometric-scale model AROME: A case study and statistics. Weather and Forecasting, 31(5):1655-1671.

Pithani, P., Ghude, S. D., Chennu, V. N., Kulkarni, R. G., Steeneveld, G.-J., Sharma, A., Prabhakaran, T., Chate, D., Gultepe, I., Jenamani, R., and Madhavan, R. (2019a). WRF model prediction of a dense fog event occurred during the winter fog experiment (WIFEX). Pure and Applied Geophysics, 176(4):1827-1846.

Pithani, P., Ghude, S. D., Prabhakaran, T., Karipot, A., Hazra, A., Kulkarni, R., Chowdhuri, S., Resmi, E., Konwar, M., Murugavel, P., Safai, P., Chate, D., Tiwari, Y., Jenamani, R., and Rajeevan, M. (2019b). WRF model sensitivity to choice of pbl and microphysics parameterization for an advection fog event at barkachha, rural site in the indo-gangetic basin, india. Theoretical and Applied Climatology, 136(3-4):1099-1113.

Possner, A., Zubler, E., Fuhrer, O., Lohmann, U., and Schär, C. (2014). A case study in modeling low-lying inversions and stratocumulus cloud cover in the Bay of Biscay. Weather and forecasting, 29(2):289-304.

Pu, Z., Chachere, C. N., Hoch, S. W., Pardyjak, E., and Gultepe, I. (2016). Numerical prediction of cold season fog events over complex terrain: the performance of the WRF model during MATERHORN-fog and early evaluation. Pure and Applied Geophysics, 173(9):3165-3186.

Ramelli, F., Beck, A., Henneberger, J., and Lohmann, U. (2020). Using a holographic imager on a tethered balloon system for microphysical observations of boundary layer clouds. Atmospheric Measurement Techniques, 13(2):925-939.

Raschendorfer, M. (2001). The new turbulence parameterization of LM. COSMO Newsletter, 1:89-97.

Reinhardt, T. and Seifert, A. (2006). A three-category ice scheme for the LMK. COSMO Newsletter, 6:115-120.

Rémy, S. and Bergot, T. (2009). Assessing the impact of observations on a local numerical fog prediction system. Quarterly Journal of the Royal Meteorological 
Society: A journal of the atmospheric sciences, applied meteorology and physical oceanography, 135(642):1248-1265.

Ritter, B. and Geleyn, J.-F. (1992). A comprehensive radiation scheme for numerical weather prediction models with potential applications in climate simulations. Monthly Weather Review, 120(2):303-325.

Roach, W., Brown, R., Caughey, S., Garland, J., and Readings, C. (1976). The physics of radiation fog: I-a field study. Quarterly Journal of the Royal Meteorological Society, 102(432):313-333.

Román Cascón, C., Yagüe, C., Sastre, M., Maqueda, G., Salamanca, F., and Viana Jiménez, S. (2012). Observations and WRF simulations of fog events at the Spanish Northern Plateau. Advances in Science and Research, 8(1):11-18.

Román-Cascón, C., Yagüe, C., Steeneveld, G.-J., Morales, G., Arrillaga, J. A., Sastre, M., and Maqueda, G. (2019). Radiation and cloud-base lowering fog events: Observational analysis and evaluation of WRF and HARMONIE. Atmospheric Research, 229:190-207.

Roquelaure, S. and Bergot, T. (2009). Contributions from a Local Ensemble Prediction System (LEPS) for improving fog and low cloud forecasts at airports. Weather and Forecasting, 24(1):39-52.

Schär, C., Leuenberger, D., Fuhrer, O., Lüthi, D., and Girard, C. (2002). A new terrain-following vertical coordinate formulation for atmospheric prediction models. Monthly Weather Review, 130(10):2459-2480.

Scherrer, S. C. and Appenzeller, C. (2014). Fog and low stratus over the Swiss Plateau - a climatological study. International Journal of Climatology, 34(3):678686.

Schmetz, J., Pili, P., Tjemkes, S., Just, D., Kerkmann, J., Rota, S., and Ratier, A. (2002). An introduction to Meteosat second generation (MSG). Bulletin of the American Meteorological Society, 83(7):977-992.

Schneider, W. and Bott, A. (2014). On the time-splitting errors of one-dimensional advection schemes in numerical weather prediction models; a comparative study. Quarterly Journal of the Royal Meteorological Society, 140(684):2321-2329. 
Schraff, C. and Hess, R. (2012). A description of the nonhydrostatic regional COSMO-model, Part III: Data assimilation. www.cosmomodel.org/content/model/documentation/core.

Schwenkel, J. and Maronga, B. (2018). Large-eddy simulation of radiation fog with comprehensive two-moment bulk microphysics: impact of different aerosol activation and condensation parameterizations. Atmospheric Chemistry and Physics 2018 (2018), 19(10):7165-7181.

Seidel, J., Ketzler, G., Bechtel, B., Thies, B., Philipp, A., Böhner, J., Egli, S., Eisele, M., Herma, F., Langkamp, T., Petersen, E., Sachsen, T., Schlabing, D., and Christoph, S. (2016). Mobile measurement techniques for local and micro-scale studies in urban and topo-climatology. DIE ERDE, 147:15-39.

Sommeria, G. and Deardorff, J. (1977). Subgrid-scale condensation in models of nonprecipitating clouds. Journal of the Atmospheric Sciences, 34(2):344-355.

Steeneveld, G., Ronda, R., and Holtslag, A. (2015). The challenge of forecasting the onset and development of radiation fog using mesoscale atmospheric models. Boundary-Layer Meteorology, 154(2):265-289.

Steeneveld, G.-J. and de Bode, M. (2018). Unravelling the relative roles of physical processes in modelling the life cycle of a warm radiation fog. Quarterly Journal of the Royal Meteorological Society, 144(714):1539-1554.

Steppeler, J., Doms, G., Schättler, U., Bitzer, H., Gassmann, A., Damrath, U., and Gregoric, G. (2003). Meso-gamma scale forecasts using the nonhydrostatic model LM. Meteorology and atmospheric Physics, 82(1-4):75-96.

Stolaki, S., Pytharoulis, I., and Karacostas, T. (2012). A study of fog characteristics using a coupled WRF-COBEL model over Thessaloniki airport, Greece. Pure and applied geophysics, 169(5-6):961-981.

Strabala, K. I., Ackerman, S. A., and Menzel, W. P. (1994). Cloud properties inferred from 8-12- $\mu \mathrm{m}$ data. Journal of Applied Meteorology, 33(2):212-229.

Strang, G. (1968). On the construction and comparison of difference schemes. SIAM Journal on Numerical Analysis, 5(3):506-517. 
Szintai, B., Szűcs, M., Randriamampianina, R., and Kullmann, L. (2015). Application of the AROME non-hydrostatic model at the Hungarian Meteorological Service: Physical parameterizations and ensemble forecasting. Időjárás, 119(2):241-265.

Tardif, R. (2007). The impact of vertical resolution in the explicit numerical forecasting of radiation fog: A case study. Pure and Applied Geophysics, 164:1221-1240.

Teixeira, J. (1999). Simulation of fog with the ECMWF prognostic cloud scheme. Quarterly Journal of the Royal Meteorological Society, 125(554):529-552.

Van der Velde, I., Steeneveld, G., Wichers Schreur, B., and Holtslag, A. (2010). Modeling and forecasting the onset and duration of severe radiation fog under frost conditions. Monthly Weather Review, 138(11):4237-4253.

Wærsted, E. G., Haeffelin, M., Dupont, J.-C., Delanoë, J., and Dubuisson, P. (2017). Radiation in fog: quantification of the impact on fog liquid water based on groundbased remote sensing. Atmospheric Chemistry and Physics, 17(17):1081110835.

Wanner, H. (1979). Zur Bildung, Verteilung und Vorhersage winterlicher Nebel im Querschnitt JuraâǍŤAlpen. Geographisches Institut der UniversitÃd't Bern.

Wanner, H. and Furger, M. (1990). The bise - Climatology of a regional wind north of the Alps. Meteorology and Atmospheric Physics, 43(1-4):105-115.

Wicker, L. J. and Skamarock, W. C. (2002). Time-splitting methods for elastic models using forward time schemes. Monthly Weather Review, 130(8):2088-2097.

Wilson, T. H. and Fovell, R. G. (2016). Modeling the evolution and life cycle of stable cold pools. Weather and Forecasting, 31(6):1753-1769.

Zhou, B., Du, J., Gultepe, I., and Dimego, G. (2012). Forecast of low visibility and fog from NCEP: Current status and efforts. Pure and Applied Geophysics, 169(56):895-909. 
7 Figures

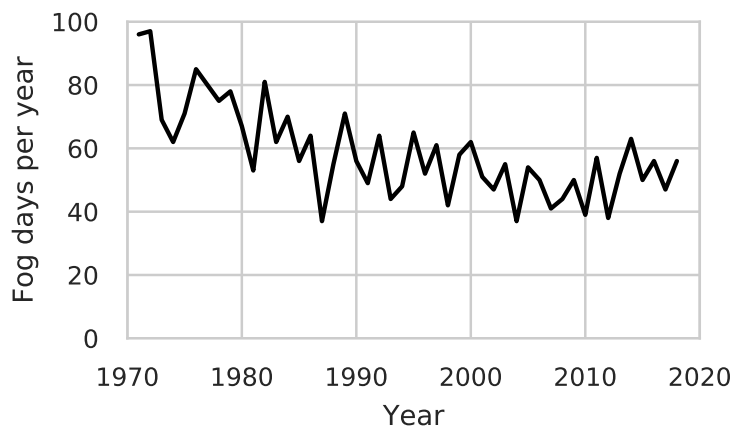

Figure 1: Days per year where a human observer reported fog (visibility below $1 \mathrm{~km}$ ) at Zürich airport (ZRH). 


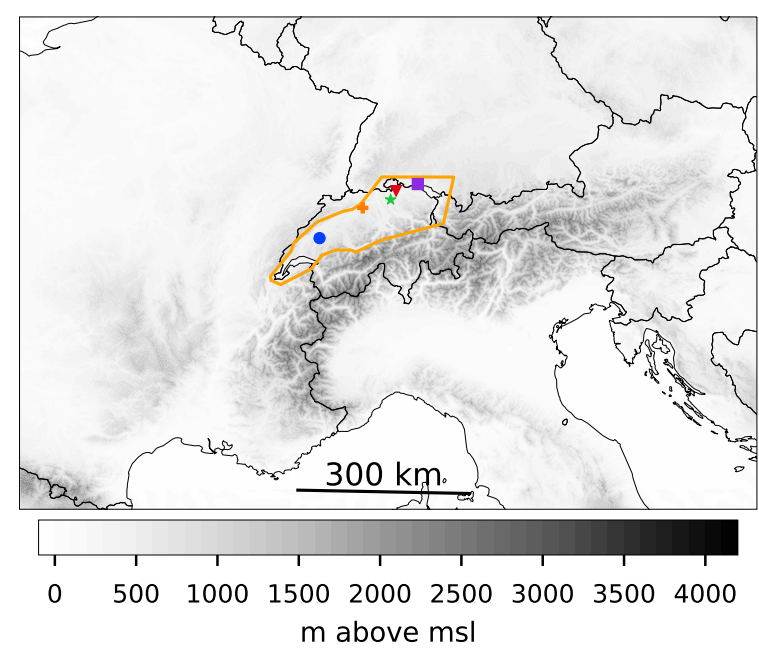

Figure 2: Computational domain of COSMO-1, the operational numerical weather prediction model of MeteoSwiss. Represented in grey shading is the surface elevation. The following locations situated within the Swiss Plateau are indicated: Payerne (PAY), blue circle; Oftringen (OFT), orange cross; Zürich airport (ZRH), green star; Andelfingen (AND), red triangle; Lake Konstanz (LAK), purple rectangle. Orange polygon indicates region used for COSMO-1 forecast evaluation.

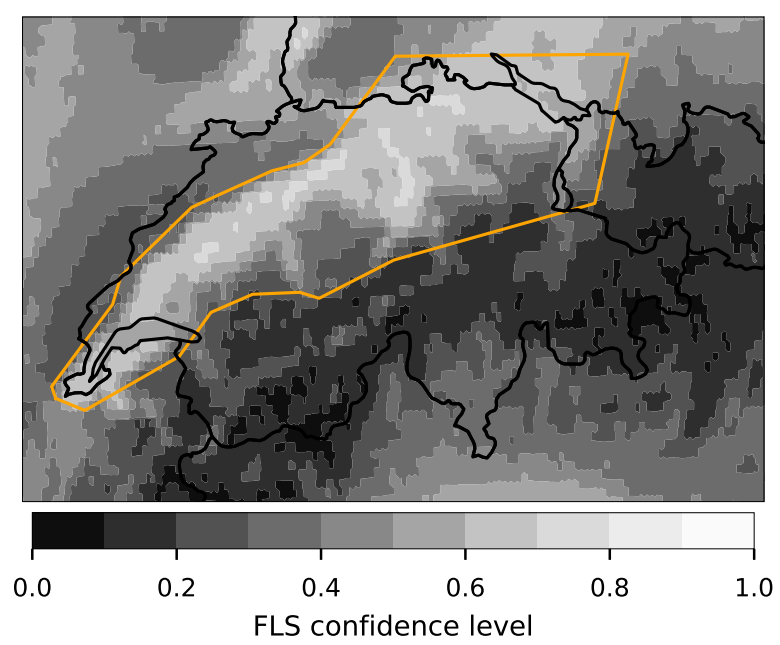

Figure 3: Validation of the FLS detection algorithm (Eq. 2) with satellite imagery averaged from November 2016 to February 2017. Values of the FLS confidence level range from 0.0 (no FLS present) to 1.0 (highest confidence of FLS occurrence). Orange polygon indicates region used for COSMO-1 forecast evaluation. 


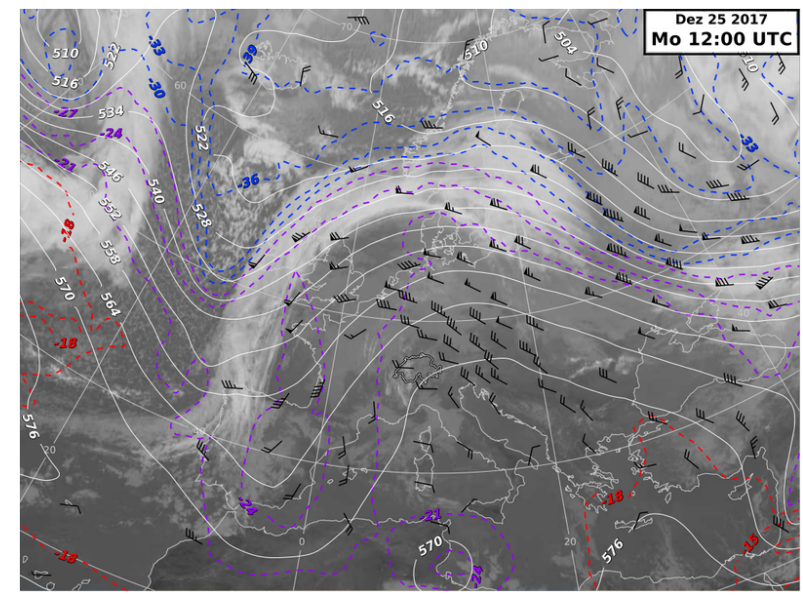

Figure 4: Synoptic setting in central Europe on December 25, 2017, 1200 UTC: Temperature (degree Celsius, dashed lines), geopotential height (geopotential decameter, solid lines) and wind (knots) at $500 \mathrm{hPa}$. A high-pressure system dominates the weather in Switzerland.

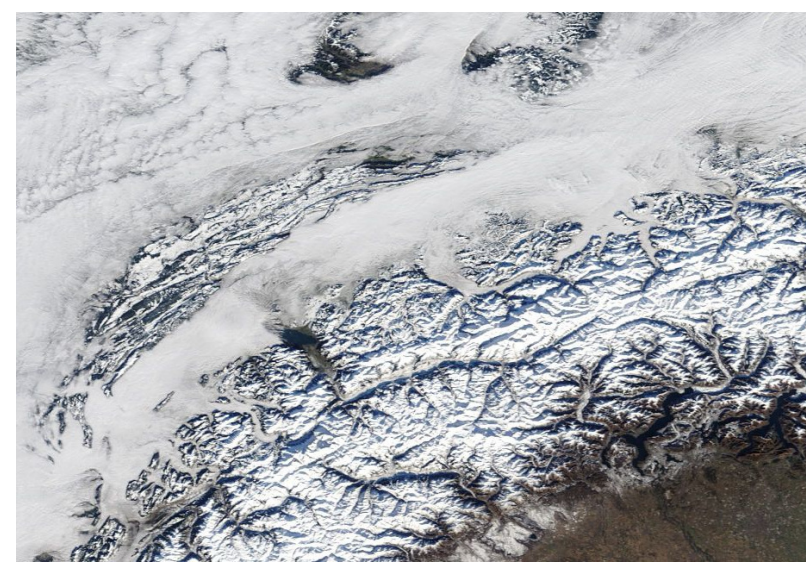

Figure 5: MODIS Terra Corrected Reflectance imagery of Switzerland on December $24,2017,10: 30$. Mountainous regions are covered in snow, most regions at lower elevation are covered by extensive FLS. FLS can easily be distinguished from snow because it is less bright and does not show any small-scale structure. Downloaded from: https://worldview.earthdata.nasa.gov. 


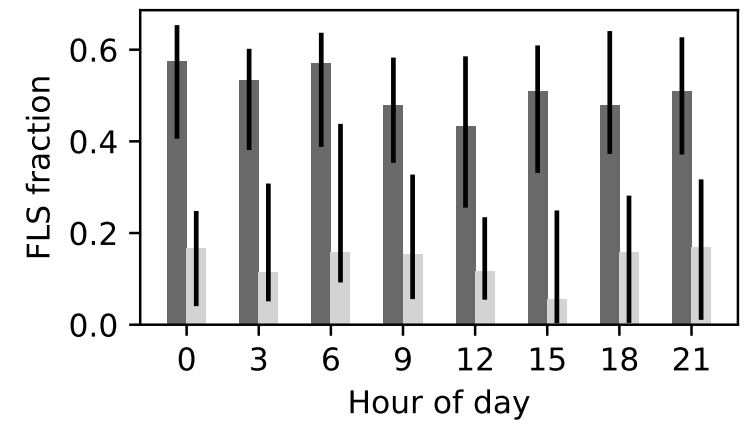

Figure 6: Median FLS fraction over the Swiss Plateau derived from satellite (dark) and COSMO-1 forecasts after 12 hours of simulation (light) for different times of day between November 2016 and February 2017. Only days where the observed FLS fraction exceeds 0.2 and the high cloud fraction is below 0.1 are included. The whiskers denote the interquartile range (IQR).

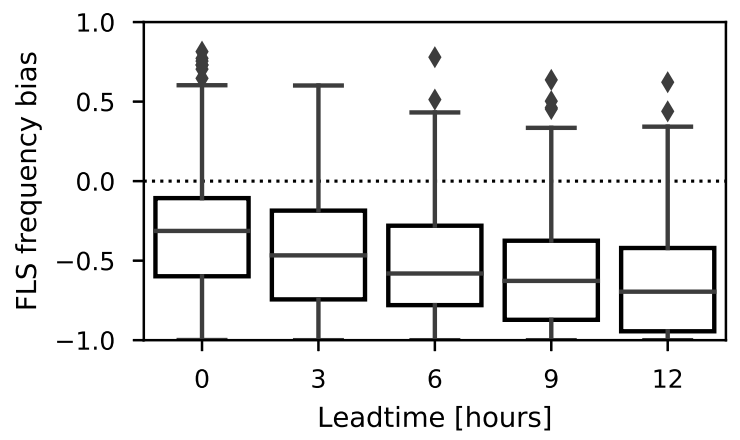

Figure 7: FLS fraction bias (COSMO-1 forecast vs satellite) for the Swiss Plateau from November 2016 to February 2017 for varying forecast leadtimes. The box shows the quartiles, the whiskers extend to show the rest of the distribution $(1.5 \times$ IQR), and outliers are denoted by a diamond. 

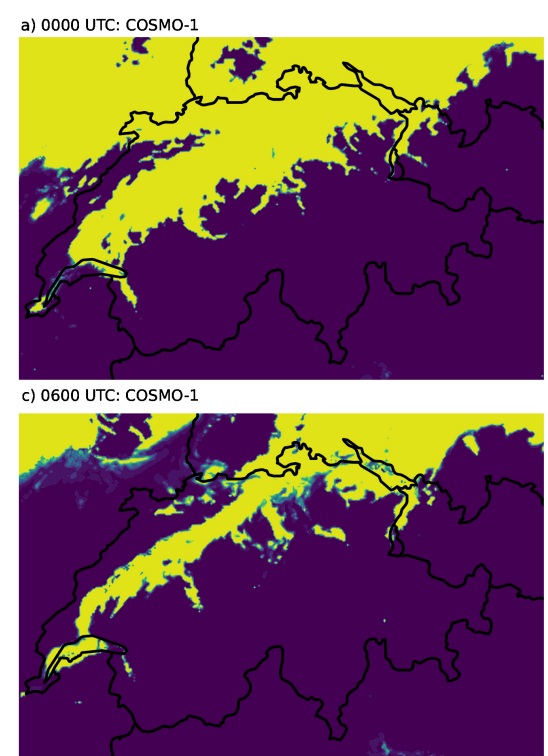

e) 1200 UTC: COSMO-1

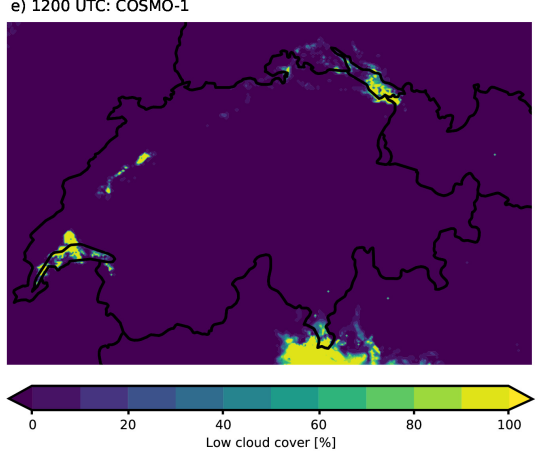

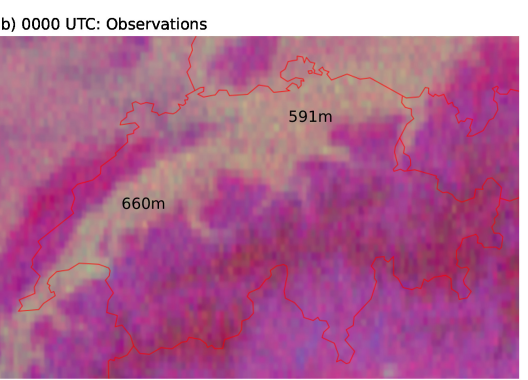

d) 0600 UTC: Observations

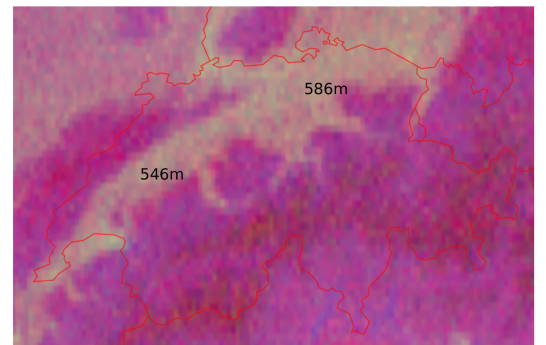

f) 1200 UTC: Observations

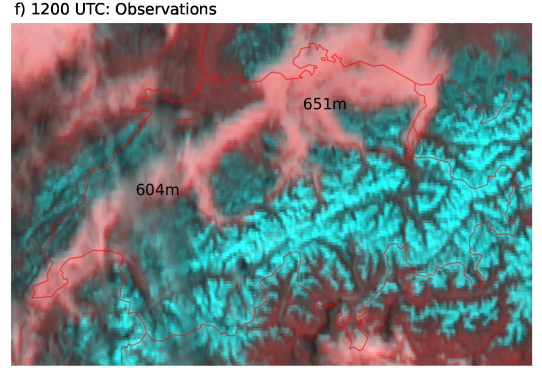

Figure 8: Comparison of FLS extent modelled by COSMO-1 forecast issued on December 25, 2017, 0000 UTC and satellite observations for 0000 UTC, 0600 UTC and 1200 UTC. FLS indicated in yellow (model) and pastel green resp. light pink (satellite) color; see www.eumetrain.org/resources/MSG_HRVfogRGB_pink_cloud.html and www.eumetrain.org/resources/MSG_nightmicro_green_cloud.html. The numbers indicate the elevation of the cloud base (in $\mathrm{m}$ asl) measured by ceilometers at Payerne and Zürich airport. 

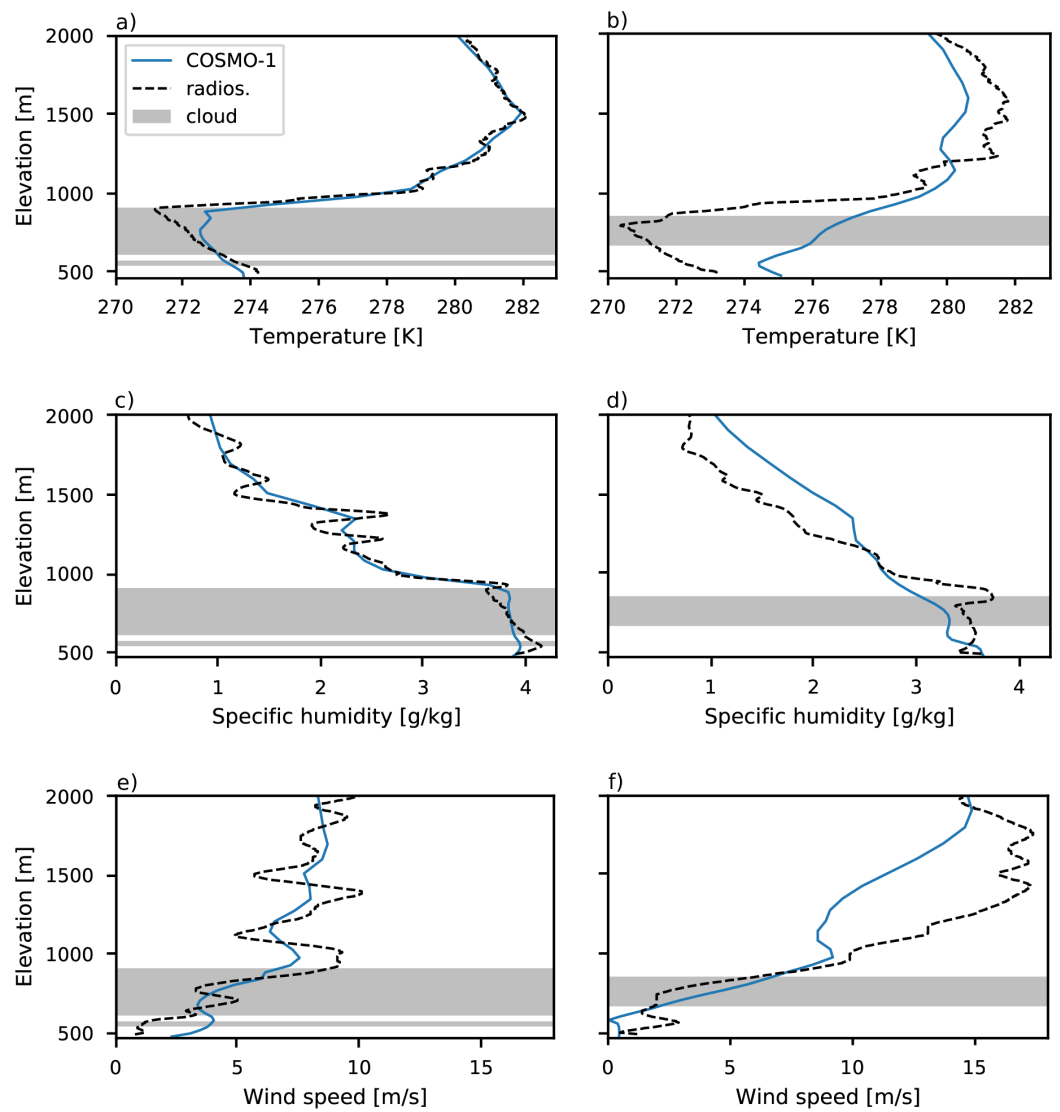

Figure 9: Vertical profiles above Payerne (PAY, blue dot in Fig. 2): Radiosounding measurements (full lines) and modelled with COSMO-1 simulation started on December 25, 2017, 0000 UTC (dashed lines): 0000 UTC (left) and +12 hours (right). Grey shaded area indicates observed cloudy layers, i.e. relative humidity $>99 \%$ (there is no modelled cloud layer, as exactly at a few grid cells around PAY, COSMO1 did not produce FLS at analysis time and at noon, all FLS clouds had already dissipated). Temperature: a), b); Specific humidity: c), d); Wind speed: e), f). 

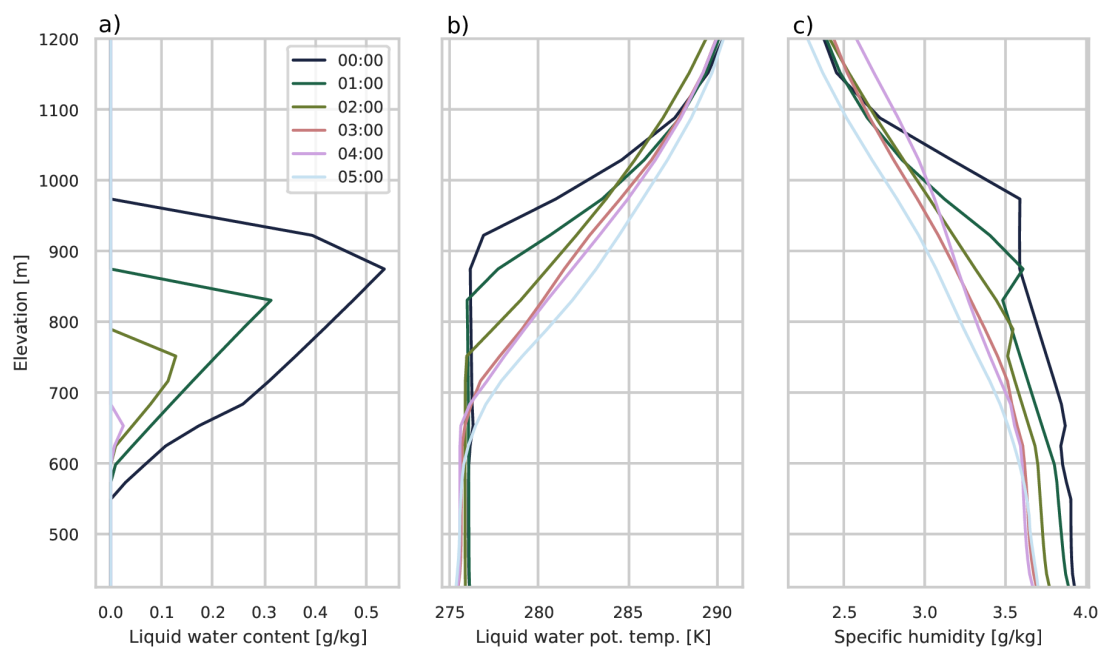

Figure 10: Hourly COSMO-1 forecast vertical profiles of a) LWC, b) liquid water potential temperature, and c) specific humidity at the grid cell of Zürich airport (green star in Fig. 2) on December 25, 2017, from 0000 UTC to 0500 UTC.

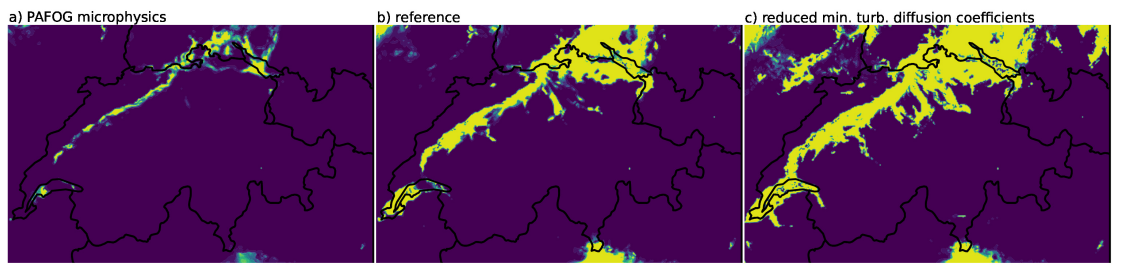

Figure 11: COSMO-1 forecasted low cloud extent on December 25, 2017, 0000 UTC: +09 hours for three different setups: a) The original one-moment scheme microphysics parameterisation is turned off and instead replaced by the two-moment scheme PAFOG (Bott and Trautmann, 2002); b) Reference simulation; c) The minimum turbulent diffusion coefficients for heat and momentum have been reduced from $0.4 \mathrm{~m}^{2} / \mathrm{s}$ to $0.01 \mathrm{~m}^{2} / \mathrm{s}$. 

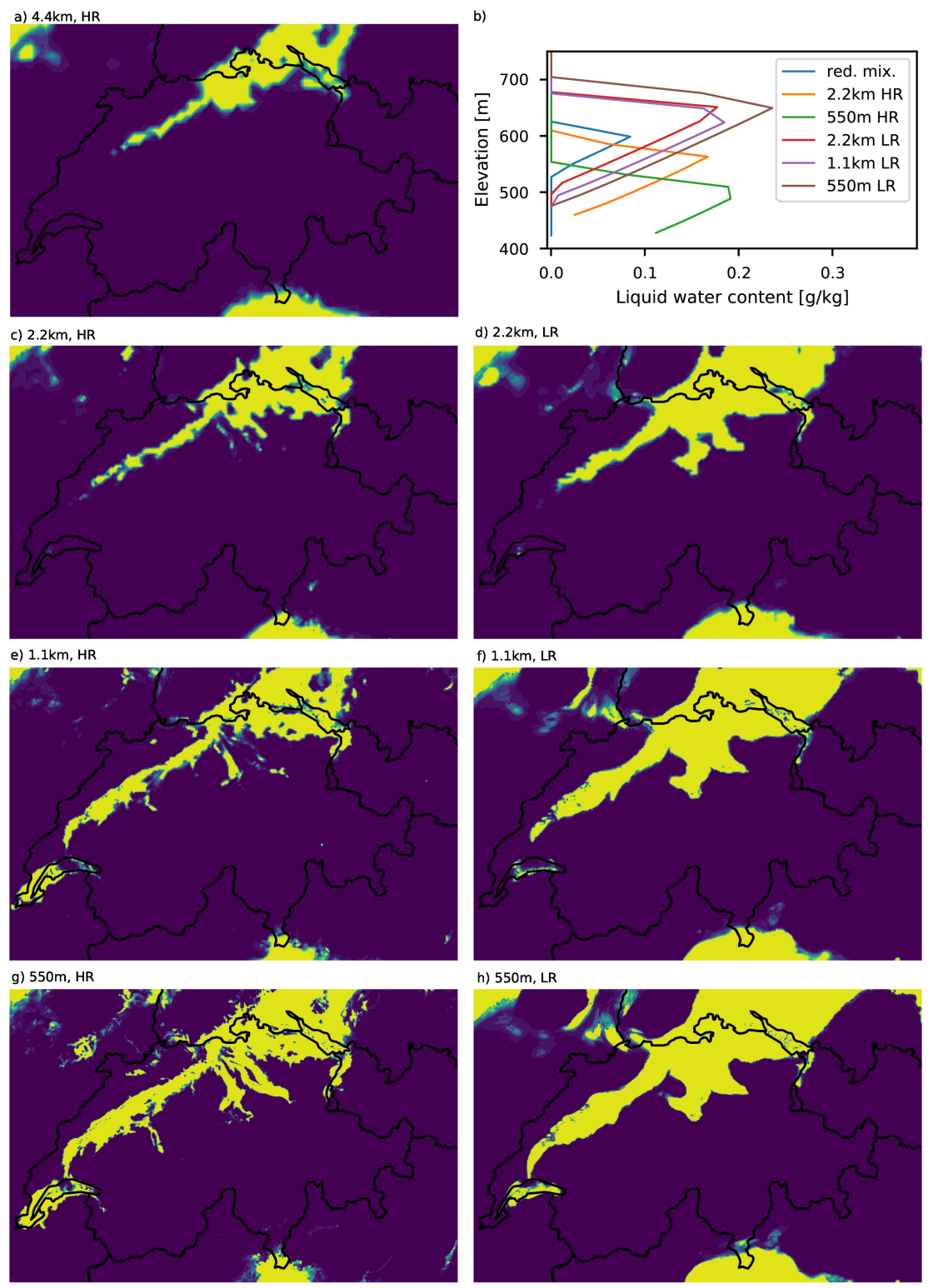

Figure 12: COSMO-1 forecasted low cloud extent on December 25, 2017, 0000 UTC: +09 hours. Grid spacings of $4.4 \mathrm{~km}(\mathrm{a}), 2.2 \mathrm{~km}(\mathrm{c}, \mathrm{d}), 1.1 \mathrm{~km}(\mathrm{e}, \mathrm{f})$, and $550 \mathrm{~m}(\mathrm{~g}, \mathrm{~h})$. The numerical grids of $d, f, h$ are derived from the $4.4 \mathrm{~km}$ grid, i.e. they contain no additional information about smaller-scale features and therefore feature lowresolution (LR) vs high-resolution (HR) orography. (b) displays the vertical LWC profiles at ZRH for these experiments (excluding those that did not exhibit any LWC) including the experiment with reduced minimum turbulent mixing coefficients (Fig. 11c). 

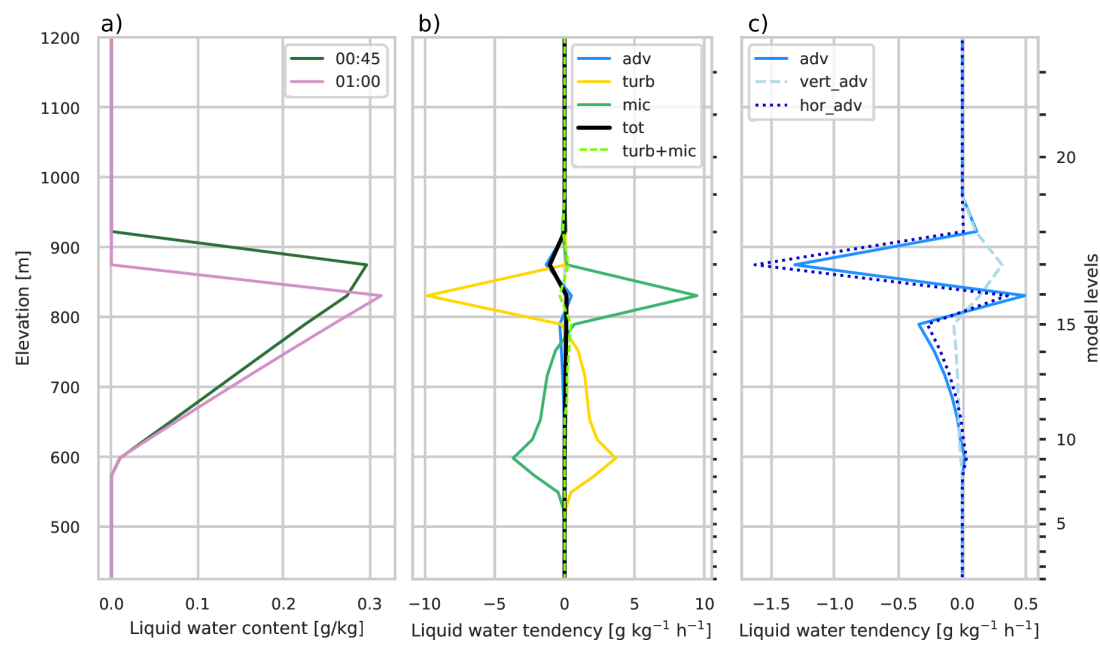

Figure 13: COSMO-1 modelled LWC budget analysis: a) Vertical LWC profile above Zürich airport (ZRH) on December 25, 2017, at 0045 UTC (dark green) and 0100 UTC (light rose). b) Corresponding total liquid water content tendency (black), contribution from advection (blue), turbulent mixing (yellow), and microphysics (green). The light green line combines the contributions from turbulent mixing and microphysics. c) Partitioning of advection tendency (blue solid) into vertical component (light blue, dashed) and horizontal component (dark blue, dotted).

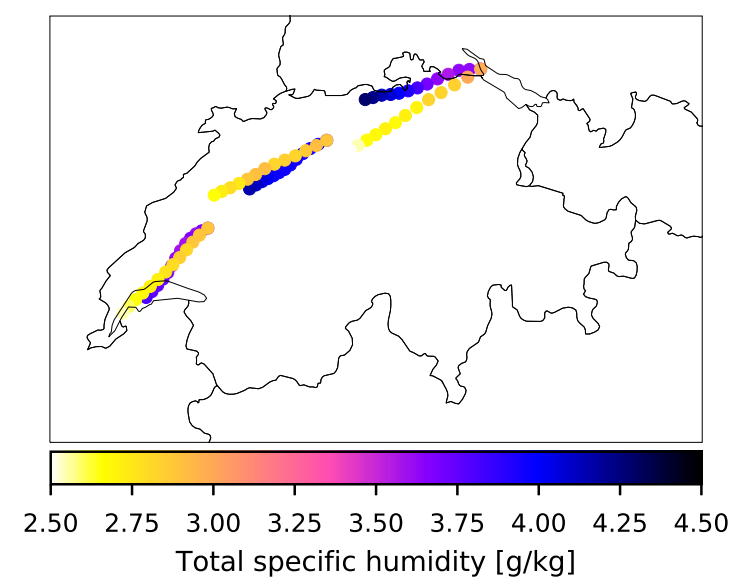

Figure 14: 3-hour backwards trajectories from December 25, 2017, 0300 UTC to 0000 UTC initialised at Payerne (PAY, left), Oftringen (OFT, centre), and LAK (right) at $800 \mathrm{~m}$ asl and $1000 \mathrm{~m}$ asl. The colour denotes the total specific humidity (combining water vapour and liquid water) at a certain grid cell. 

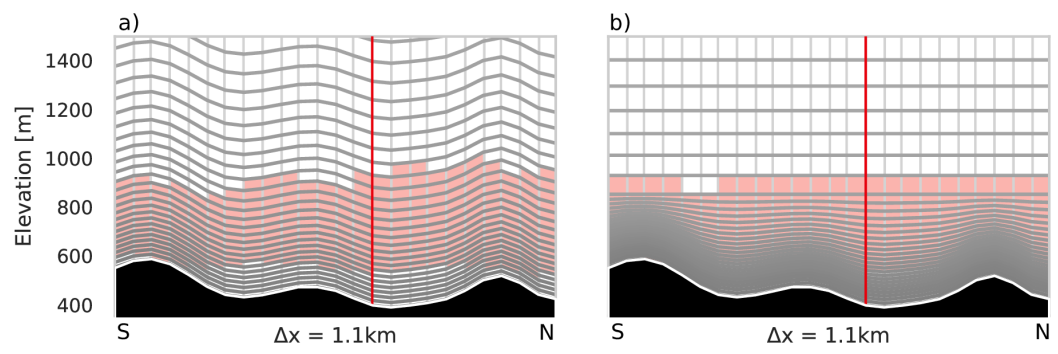

Figure 15: Computational grid along south-north cross section through Andelfingen (AND, vertical red line, location in Figure 2 indicated with red triangle): a) $h_{\text {flat }}=11,357 \mathrm{~m}$ asl and b) $h_{\text {flat }}=850 \mathrm{~m}$ asl. Rose shading displays cloud extent at the beginning of the COSMO-1 simulation of December 25, 2017, 0000 UTC.
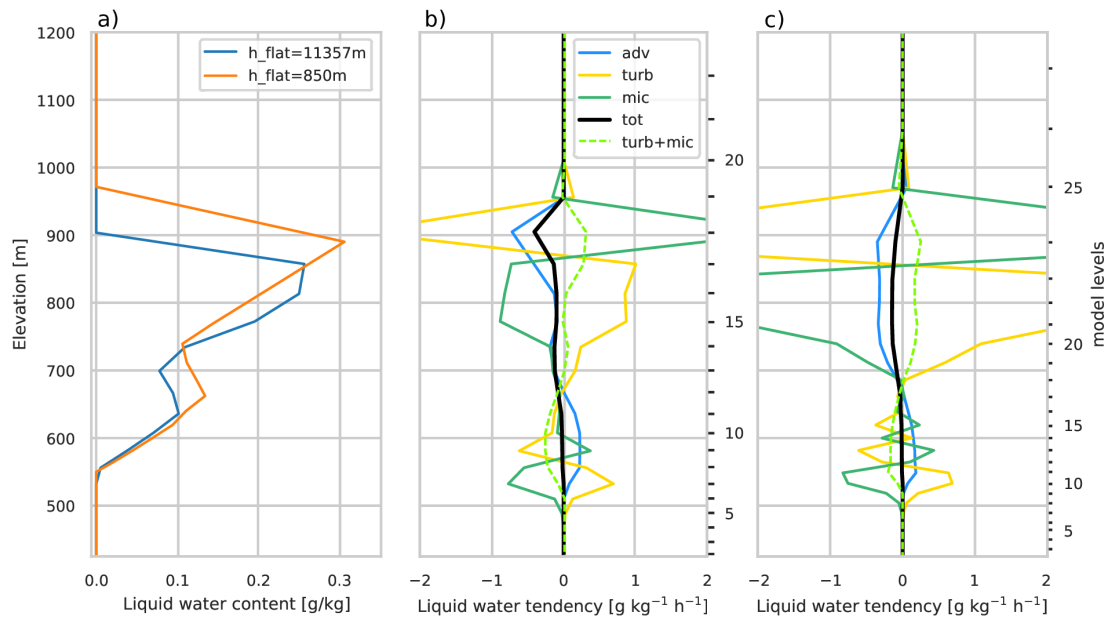

Figure 16: Vertical profile of LWC (a) and corresponding budget analysis (b: $h_{\text {flat }}=11,357 \mathrm{~m}$ asl; c: $h_{\text {flat }}=850 \mathrm{~m}$ asl) above AND. Blue line in (a): $h_{\text {flat }}=11,357 \mathrm{~m}$ asl, orange line in (a): $h_{\text {flat }}=850 \mathrm{~m}$ asl, the colours of the budget analysis as in Figure 13. 
A Appendix: Additional Figures 


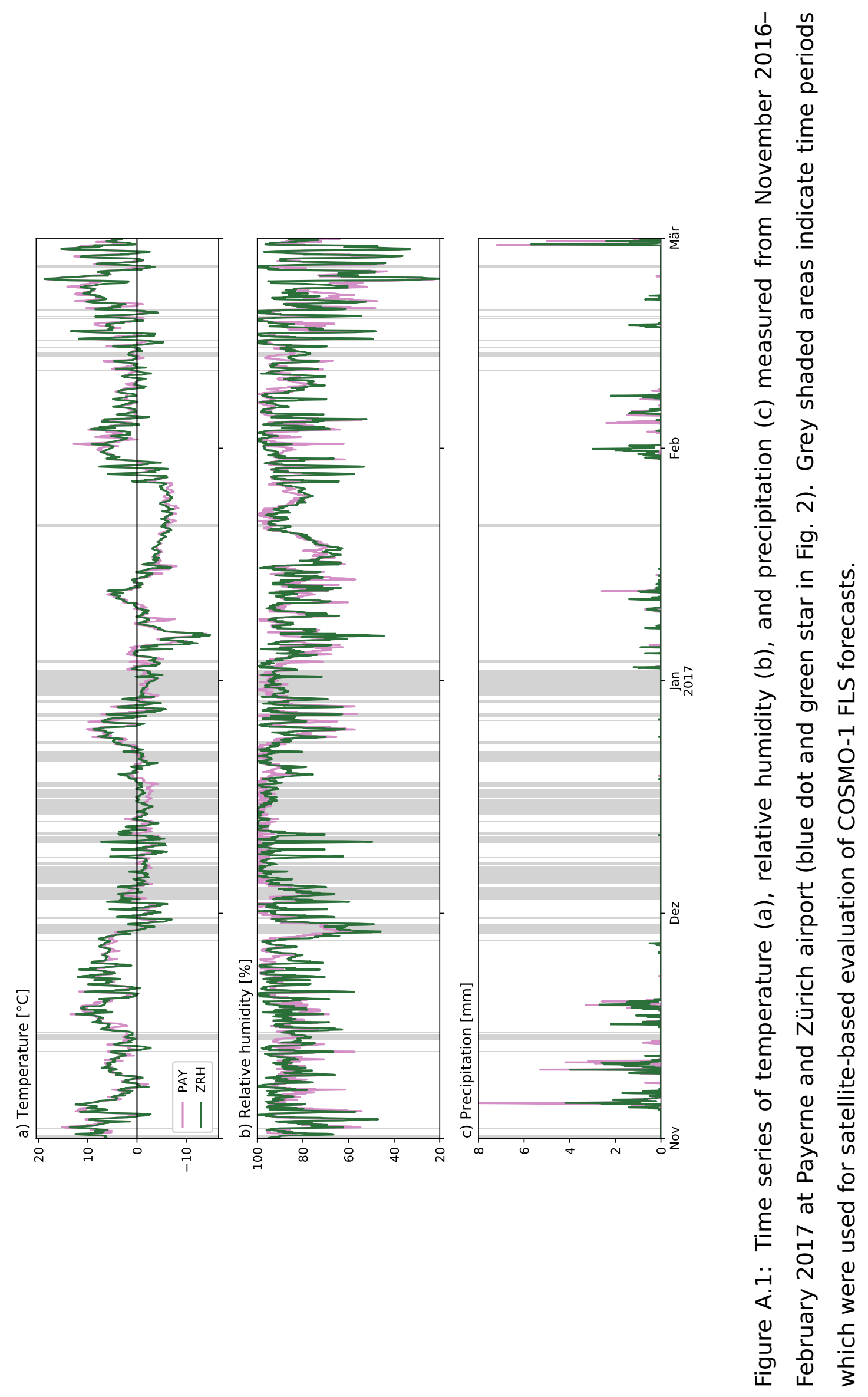




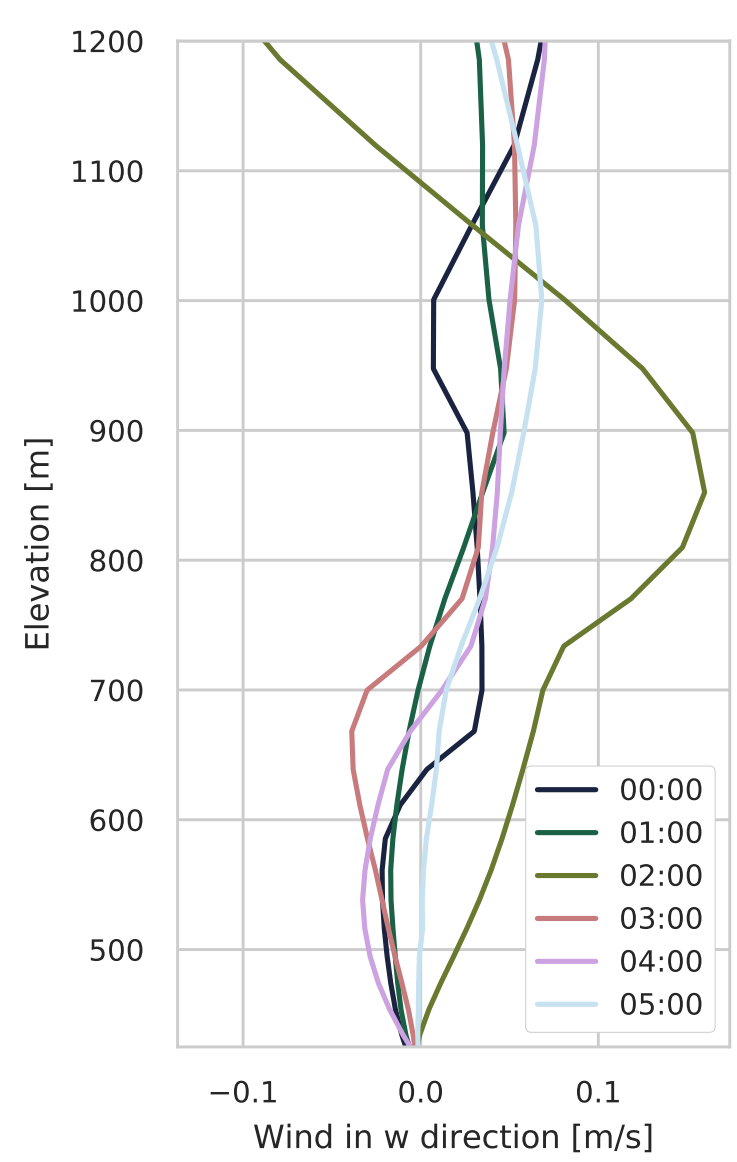

Figure A.2: Hourly COSMO-1 forecast vertical profile of vertical wind at the grid cell of Zürich airport (green star in Fig. 2) on December 25, 2017, from 0000 UTC to 0500 UTC. 